\title{
Carcharodontosaurian remains (Dinosauria, Theropoda) from the Upper Jurassic of Portugal
}

\author{
Elisabete Malafaia, ${ }^{1,2}$ Pedro Mocho, ${ }^{3,2,4}$ Fernando Escaso, ${ }^{2}$ Pedro Dantas,, 4 and Francisco Ortega ${ }^{2}$ \\ ${ }^{1}$ Instituto Dom Luiz, Universidade de Lisboa. Edifício C6. Campo Grande. 1749-016 Lisboa, Portugal 〈emalafaia@gmail.com〉 \\ ${ }^{2}$ Grupo de Biología Evolutiva. Facultad de Ciencias. Universidad Nacional de Educación a Distancia. C/ Senda del Rey, 9, 28040 Madrid, Spain \\ 〈fescaso@ccia.uned.es; fortega@ccia.uned.es〉 \\ ${ }^{3}$ Dinosaur Institute, Natural History Museum of Los Angeles County, 900 Exposition Blvd. Los Angeles, CA 90007, USA 〈p.mocho@ nhm.org〉 \\ ${ }^{4}$ Laboratório de Paleontologia e Paleoecologia, Sociedade de História Natural. Polígono Industrial do Alto do Ameal, Pav. H02 e H06, Torres \\ Vedras, Portugal \\ ${ }^{5}$ Museu da Comunidade Concelhia da Batalha. Largo Goa, Damão e Diu, no 4, 2440-901 Batalha, Portugal, 〈pedromdantas@gmail.com〉
}

\begin{abstract}
A new specimen of a theropod dinosaur found in the Upper Jurassic (Freixial Formation, late Tithonian) of the Lusitanian Basin is described. It corresponds to a single individual and includes a sequence of articulated caudal vertebrae, an almost complete right pes, and other fragments of the appendicular skeleton. The specimen includes the most complete pes of a theropod dinosaur currently known in the Lusitanian Basin and represents one of the youngest skeletal records of theropod dinosaurs currently known in the Portuguese Upper Jurassic.

A systematic analysis of this specimen is performed and it shows a combination of characters that allows us to interpret it as belonging to an allosauroid taxon. Within this clade, the material from Cambelas shares a few features with some carcharodontosaurids, including the presence of a lateral lamina extending along the anterior end of the centrum in the caudal vertebra and of a low vertical crest on the lateral surface of the femoral lesser trochanter. The set of remains described here shares some unusual features with another specimen previously described in the Portuguese fossil record, which also presents some synapomorphies of Carcharodontosauria. However, no autapomorphy or exclusive character combination can be recognized in the specimen here described in order to describe it as a new form. The presence of this specimen suggests a greater diversity in the allosauroid theropod fauna from the Late Jurassic of the Lusitanian Basin than currently known and probably expands the temporal record of Carcharodontosauria up to upper Tithonian of southwestern Europe.
\end{abstract}

\section{Introduction}

The currently known Portuguese record of theropod dinosaurs is relatively abundant and diverse, especially in the Upper Jurassic strata of the Lusitanian Basin (e.g., Lapparent and Zbyszewski, 1957; Antunes and Mateus, 2003; Mateus et al., 2006; Ortega et al., 2006). Despite some classical occurrences of theropod remains, corresponding mainly to isolated elements (Sauvage, 1897-1898; Lapparent and Zbyszewski, 1957), it was not until the end of the $20^{\text {th }}$ century that the understanding of this record improved. The specimens described by Sauvage (1897-1898) and Lapparent and Zbyszewski (1957) were assigned to different species of Megalosaurus, at that time a poorly understood taxon represented by some material from the Middle Jurassic of Stonesfield (Oxfordshire, UK), and several other fossils from different ages worldwide (Benson, 2008, 2010; Carrano et al., 2012; Rauhut et al., 2016). Most of the classical occurrences of theropod dinosaurs from the Upper Jurassic of Portugal were referred to Megalosaurus insignis Eudes-Deslongchamps and Lennier in Lennier, 1870, or to a supposedly exclusive Portuguese form, Megalosaurus pombali Lapparent and Zbyszewski, 1957 (Sauvage, 1897-1898; Lapparent and Zbyszewski, 1957).
These specimens were later reinterpreted as belonging to indeterminate theropods or assigned to other dinosaur groups (Mateus, 2005; Mocho et al., 2016).

The Portuguese Upper Jurassic fossil record includes mainly medium- to large-sized forms belonging to earlydiverging theropod clades, such as Ceratosauria, or basal tetanurans, including Megalosauroidea and Allosauroidea (e.g., Mateus, 1998; Pérez-Moreno et al., 1999; Mateus and Antunes, 2000a, 2000b; Rauhut and Fechner, 2005; Mateus et al., 2006; Malafaia et al., 2010, 2015; Araújo et al., 2013; Hendrickx and Mateus, 2014a, 2014b). Small-sized and more derived theropod dinosaurs have also been identified in this record, based mainly on isolated elements (Zinke, 1998; Rauhut, 2003a; Hendrickx and Mateus, 2014b; Malafaia et al., 2014).

Most of the theropod specimens currently known in the Upper Jurassic of the Lusitanian Basin come from sedimentary rocks of the Praia da Amoreira-Porto Novo Formation (sensu Manuppella et al., 1999) in the coastal region of the Bombarral Sub-basin (corresponding to the Consolação Sub-basin, sensu Taylor et al., 2014). This formation is interpreted as late Kimmeridgian in age and crops out along most of the littoral region between Torres Vedras and Peniche. Scarce, but scientifically 
important fossil sites with theropod specimens are known at the northern area of the Bombarral Sub-basin, such as the Guimarota mine, near Leiria (Zinke, 1998; Rauhut and Fechner, 2005), or the Andrés fossil site, near Pombal (Malafaia et al., 2010). Theropod material is currently unknown from the Arruda Sub-basin, located in the SE part of the central sector of the Lusitanian Basin, and only few occurrences are known from the Turcifal Sub-basin (Lapparent and Zbyszewski, 1957), which is located west of the Arruda Sub-basin and is bounded on the north by the Torres Vedras-Montejunto fault and on the east by the Runa fault.

Here we describe a partial postcranial skeleton of a theropod dinosaur (preliminarily described by Malafaia et al., 2007) found in the coastal region of the northern part of the Turcifal Sub-basin, at the Cambelas locality (Torres Vedras municipality). This specimen together with a previously described specimen, SHN.036 (Malafaia et al., 2017), may represent an allosauroid distinct from the taxa currently known in the Upper Jurassic of the Lusitanian Basin, such as the allosaurid Allosaurus and the possible metriacanthosaurid Lourinhanosaurus. A systematic discussion of the specimen is presented and the diversity of allosauroid theropods in the Late Jurassic of the Lusitanian Basin is discussed.

\section{Geologic setting}

The Cambelas fossil site (TVSPC 12 in the Geographic Information System Applied to Palaeontology of the Sociedade de História Natural-SIGAP database) is situated in the littoral area of the southern end of Torres Vedras municipality, $\sim 45 \mathrm{~km}$ north from Lisbon. This locality is placed in the central sector of the Lusitanian Basin, in the northern part of the Turcifal Subbasin (Fig. 1).

The strata in the area of Cambelas consists of a sequence of thick red mudstones, with abundant levels of well-developed pedogenic carbonate concretions (caliche), intercalated with cross-bedded sandstones. These sediments are interpreted as belonging to the Freixial Formation dated from the late Tithonian, based on foraminifera and dasycladaceans (Leinfelder, 1993; Kullberg et al., 2006; Schneider et al., 2009). The top boundary of the Freixial Formation is defined by the transition from a mudstone-dominated sequence to the richest sandstone levels of the Lower Cretaceous Porto da Calada Formation (Rey, 1993). The Freixial Formation in the area of Cambelas is interpreted as corresponding to deposits of coastal delta plains and distal fluvial environments (Hill, 1988).

The set of osteological remains collected in Cambelas is interpreted as belonging to a single individual. The caudal vertebrae are articulated and the elements of the right pes were found associated and near their original relative positions. Some elements are well preserved and relatively complete, but others are poorly preserved, incomplete, and distorted. In particular, the most-anterior elements of the preserved and partially articulated caudal series are strongly distorted and damaged, lacking several parts of the vertebrae. The differences in preservation of the bones coincide with a sedimentological transition from gray siltstones with parallel lamination, which contained the posterior and well-preserved part of the sequence and the elements of the pes, to red and brown mudstones with evidence of incipient paleosols, where the anterior elements of the tail and other fragmentary elements of the hind limb and pelvic girdle were found. This suggests that parts of the skeleton would have been rapidly covered by sediments, whereas other parts were exposed longer. On the other hand, several ichnofossils were identified in some elements of the Cambelas specimen, which were interpreted as marks of different activities of organisms in a subaerial depositional context and that might have had an important role in the distortion and decomposition of some elements (Moniz et al., 2007). Evidence of tooth marks and abundant marks interpreted as insect traces are among these ichnofossils. The study of these ichnofossils is in preparation and will be presented in a forthcoming work.

\section{Materials and methods}

SHN.019 consists on a partial skeleton, including a sequence of articulated mid-distal caudal vertebrae and an almost complete right pes. Several other isolated elements, such as caudal vertebrae and fragments of the hind limbs, were also collected and included into the same specimen. In the Cambelas fossil site (locality TVSPC 12) some isolated elements of other vertebrate groups were also found, including a vertebra and a tooth fragment of a crocodyliform and a tooth of an indeterminate small theropod (see Supplementary Data 1 for a complete list of osteological remains collected at the Cambelas fossil site).

The nomenclature used in the description of pneumaticity, laminae, and fossae for the axial elements is that proposed by Wilson (1999) and Wilson et al. (2011). Following Persons and Currie (2011), the lateral projections of caudal vertebrae are here referred to as "caudal ribs" in preference to the term "transverse processes."

Repositories and institutional abbreviations.-The specimens described here are housed in the collections of the Sociedade de História Natural (SHN) in Torres Vedras; BYU, Brigham Young University, Provo, Utah, USA; DMNS, Denver Museum of Nature \& Science, Denver, Colorado, USA; DINO, Dinosaur National Monument, Jensen, Utah, USA; MfN, Museum für Naturkunde, Berlin, Germany; ML, Museu da Lourinhã, Lourinhã, Portugal; MNHN, Muséum national d'Histoire naturelle, Paris, France; MUHNAC, Museu Nacional de História Natural e da Ciência, Universidade de Lisboa, Lisbon, Portugal; NCSM, North Carolina State Museum of Natural Sciences, Raleigh, North Carolina, USA; NHMLAC, Natural History Museum of Los Angeles County, Los Angeles, California, USA; NHMU, Natural History Museum of Utah, Salt Lake City, Utah, USA; NHMUK, Natural History Museum, London, UK; and OUMNH, Oxford University Museum of Natural History, Oxford, UK.

\section{Systematic paleontology}

Dinosauria Owen, 1842

Theropoda Marsh, 1881

Tetanurae Gauthier, 1986

Avetheropoda Paul, 1988

Allosauroidea Marsh, 1878 

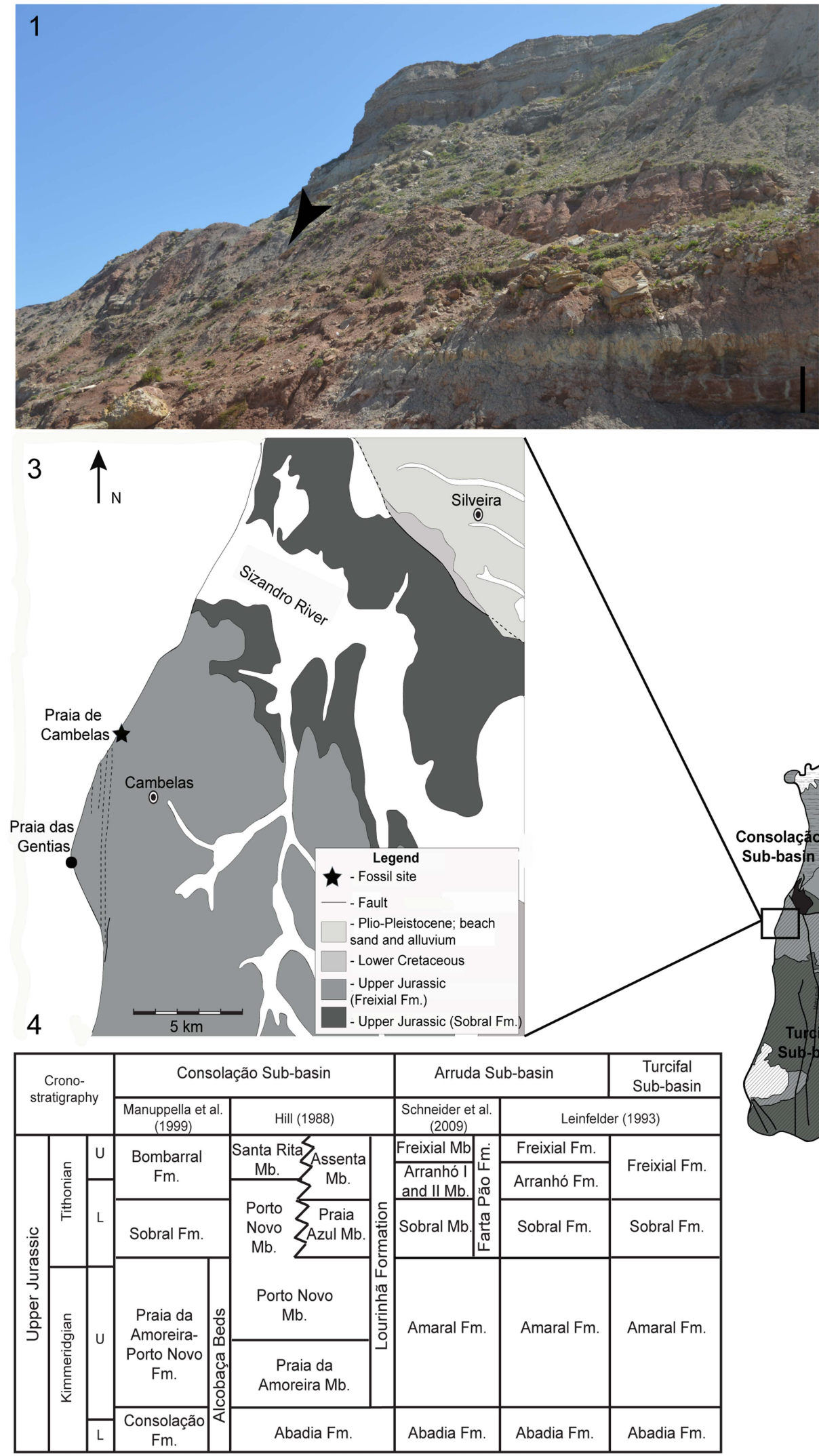

2 
Carcharodontosauria Benson, Carrano, and Brusatte, 2010 Genus and species indeterminate

Figures 2-10

Description.-SHN.019 includes a sequence of articulated caudal vertebrae with chevrons, two isolated caudal centra, an almost complete right pes, and fragments of the hind limbs. The axial skeleton includes a block containing seventeen articulated and well-preserved caudal vertebrae with the respective chevrons and fragments of other more-anterior caudal centrum. Additionally, two isolated anterior caudal certebrae were recovered. Several appendicular elements were also collected, including fragments of a right femur, a diaphysis fragment of a tibia, a diaphysis fragment of a left fibula, at least two proximal tarsals, and an almost complete right pes.

Caudal Vertebrae.-The two isolated caudal vertebrae both preserve the centra and the base of the neural arches (Fig. 2). The neural arches are fused with the centra, but the neurocentral suture is still visible. The centra are moderately elongated with strongly offset articular facets and shallow pleurocentral depressions on the lateral surface. The pleurocentral depression is dorsally located near the base of the neural arch and occupies almost the entire length of the centrum. The ventral surface of the centrum has a well-developed longitudinal groove bounded by crests extending along most of its length, which become deeper adjacent to the posterior articular facet. The articular facets are strongly concave with a sub-circular outline (Supplementary Data 2). Well-developed facets for chevrons are visible on the ventral margin of both anterior and posterior articular facets, with the posterior facet larger than the anterior one. In SHN.019/3, a small pit is visible in the posterior surface of the neural arch, below the left postzygapophysis.

The articulated section of the tail measures $1560 \mathrm{~mm}$ in length and comprises eight vertebrae anterior to the so-called "transition point," which refers to the point between the last vertebra bearing transverse processes (caudal ribs) and the first with distinctly elongate prezygapophyses (sensu Russell, 1972), and nine vertebrae posterior to this point (Figs. 3, 4). Taking for comparison other allosauroids, in which the "transition point" is placed at approximately the $25^{\text {th }}$ or $26^{\text {th }}$ caudal vertebra (e.g., Madsen, 1976; Chure, 2000), the articulated caudal vertebrae from Cambelas would correspond to a section of the tail between the $17^{\text {th }}$ or $18^{\text {th }}$ and the $34^{\text {th }}$ or $35^{\text {th }}$ caudal vertebrae. These vertebrae are well preserved, but the anteriormost elements are somewhat broken and distorted, especially the neural arches. Almost all the chevrons are attached intervertebrally in the preserved tail section.

The centra are moderately elongated. The length/height ratio average is $\sim 1.94$ in the anteriormost vertebrae, and the centra become slightly more elongated towards the tip of the tail (see Supplementary Data 2). The centra are transversely compressed, especially in the anteriormost caudal vertebrae, and they have well-marked longitudinal grooves in the ventral surface, as in the isolated caudal vertebra described above (Fig. 4). These grooves become progressively shallower along the caudal series and disappear in the centra posterior to the "transition point." In lateral view, the mid-anterior centra are
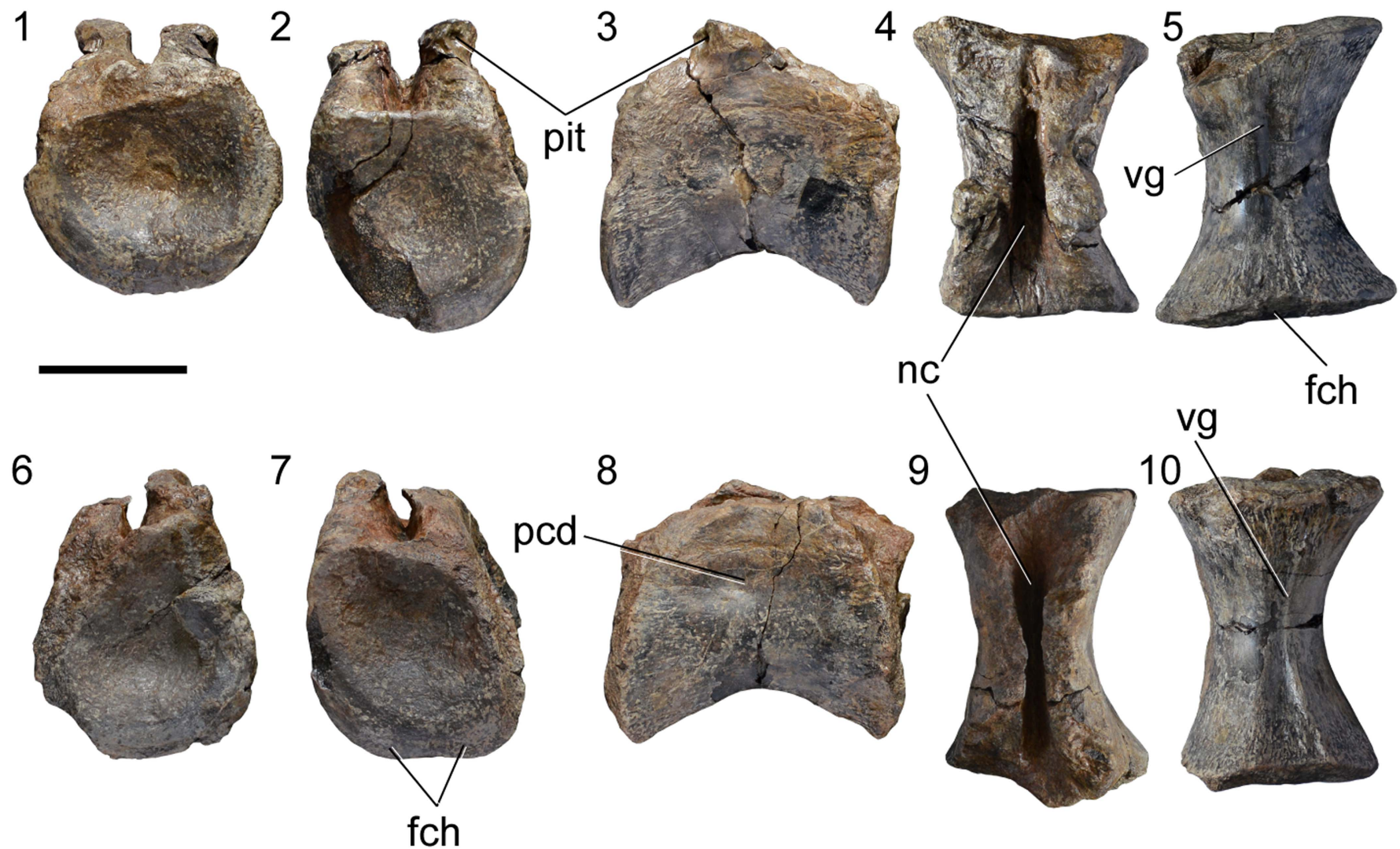

Figure 2. Isolated caudal vertebrae of SHN.019. (1-5) SHN.019/3; (6-10) SHN.019/4, in anterior $(\mathbf{1}, \mathbf{6})$, posterior $(\mathbf{2}, \mathbf{7})$, right lateral (3, 8), dorsal (4, 9), and ventral $(\mathbf{5}, \mathbf{1 0})$ views. Abbreviations: fch, facet for chevron; nc, neural canal; pcd, pleurocentral depression; pit, pit; vg, ventral groove. Scale bar $=50 \mathrm{~mm}$. 


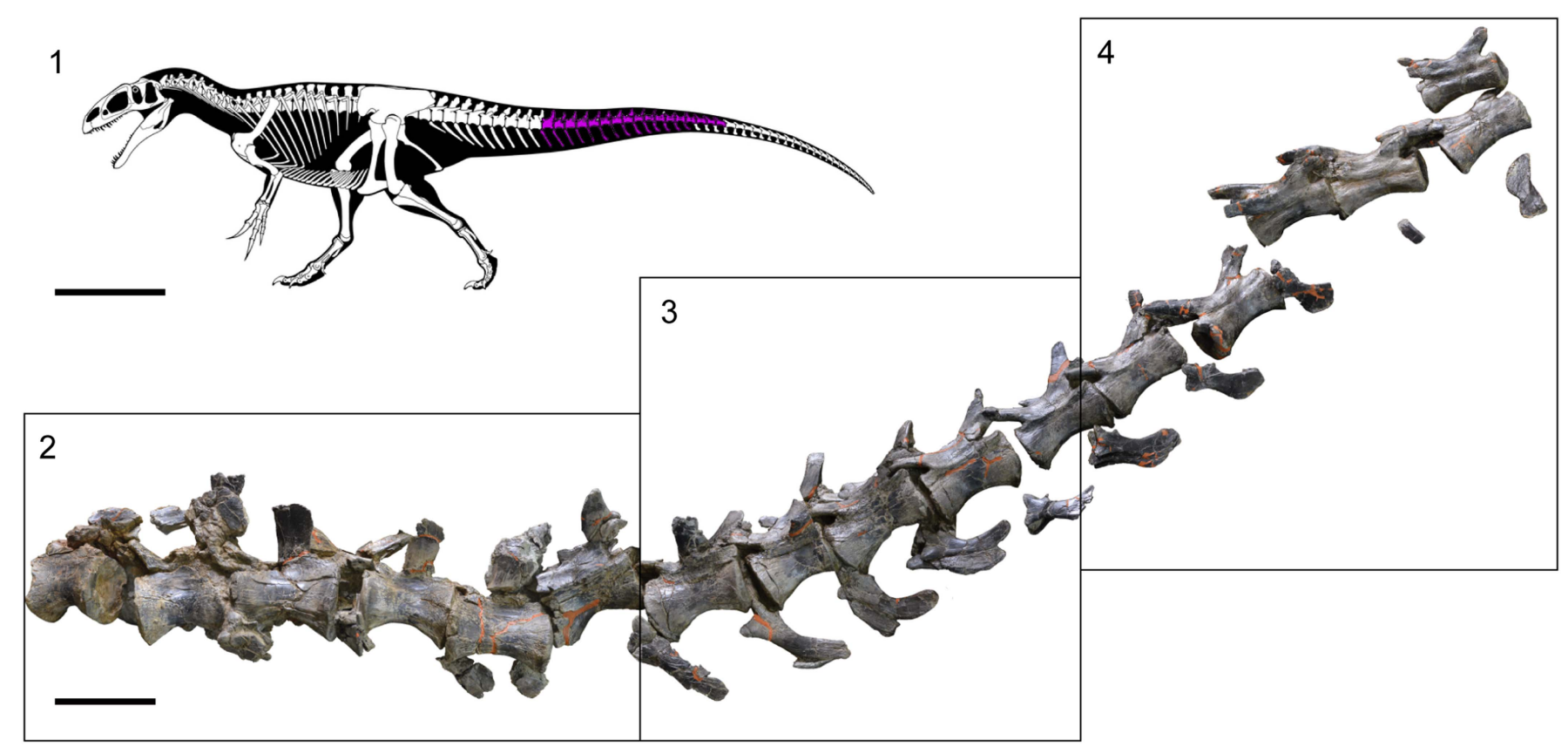

Figure 3. Sequence of caudal vertebrae of SHN.019. (1) Reconstitution of the skeleton of a Neovenator individual (copyright of the skeleton of Neovenator Scott Hartman, 2013) in which the estimated position of the tail section collected in Cambelas is marked; (2-4) sequence of seventeen partially articulated caudal vertebrae of SHN.019. Scale bar $=1 \mathrm{~m}(\mathbf{1})$ or $100 \mathrm{~mm}(\mathbf{2})$.

hourglass-shaped, deeply concave ventrally, and with strongly expanded articular facets, but become straighter towards the tip of the tail. The lateral surface of the anteriormost centra is somewhat concave, with a shallow pleurocentral depression below the caudal ribs. However, the centra posterior to the fifth caudal vertebra in the preserved series are slightly convex.

The ventral surface of the centra has well-developed anterior and posterior facets for the chevrons, with the posterior facets being larger than the anterior ones, as is typical in theropods. In the last two preserved vertebrae, the facets for the chevrons are reduced and almost indistinguishable. The neural spines are poorly preserved, especially in the most anterior elements, so their interpretation is somewhat complex. However, the sixth caudal vertebra of the preserved series has an almost complete neural spine, which consists of an anterior, spur-shaped process and a long, blade-shaped main spine extending to the rear (Fig. 4). The anterior spur projects dorsally from about the level of the caudal ribs, whereas the posterior process projects dorsoposteriorly between the postzygapophyses. A well-developed spinopostzygapophyseal lamina (spol) projects from the dorsomedial surface of the postzygapophysis, connecting it with the posterior surface of the spine. This lamina extends along most of the height of the neural spine. The neural spines are visible at least up to the sixth caudal vertebra posterior to the transition-point (corresponding to the $31^{\text {st }}$ or $32^{\text {nd }}$ vertebra in the caudal series). In this vertebra, the neural spine is still well visible above the dorsal margin of the postzygapophyses. In the last preserved vertebra, a reduced process of the spine is visible, but is much lower than the dorsal margin of the postzygapophyses. This condition differs from the caudal series of Allosaurus, in which the neural spines become reduced at approximately the $28^{\text {th }}$ caudal vertebra (Madsen, 1976).
The prezygapophyses are short in the anteriormost preserved caudal vertebrae, extending only slightly in front of the anterior articular facet. In the posterior part of the series, the prezygapophyses become progressively longer, and in the posteriormost preserved elements, the length of the prezygapophyses surpasses half the length of the preceding centrum. The prezygapophyseal processes project anterodorsally, forming an angle of $\sim 45^{\circ}$ with the dorsal surface of the centrum. The lateral surface of the prezygapophysis is slightly concave in the anteriormost preserved vertebrae, but becomes almost flat with a low longitudinal crest towards the tip of the tail. The postzygapophyses of the anteriormost caudal vertebrae are poorly preserved and are not visible because of the articulation of the vertebrae. In the sixth caudal vertebra of the preserved series, the postzygapophyses are relatively well preserved, corresponding to short processes that project dorsally in an angle of nearly $60^{\circ}$ with respect to the dorsal surface of the centra.

In the second caudal vertebra of the preserved caudal series, a well-developed lamina projects from the lateral surface of the base of the prezygapophysis and apparently would have connected with the caudal rib, bounding a small, but deep fossa bellow the caudal rib (Fig. 4.1). These lamina and fossa are interpreted as corresponding to the prezygodiapophyseal lamina (prdl) and centroprezygapophyseal fossa (cprf), respectively. A well-developed centroprezygapophyseal lamina (cprl) is visible in some vertebrae, projecting from the anterior margin of the prezygapophysis up to the level of the base of the caudal rib on the centrum. Some vertebrae (e.g., the sixth and eighth of the preserved series) show well-developed centropostzygapophyseal laminae (cpol) extending from the posterior part of the postzygapophysis up to the dorsal surface of the centrum above the level of the caudal rib (Fig. 4.2, 4.3). In the eighth preserved 

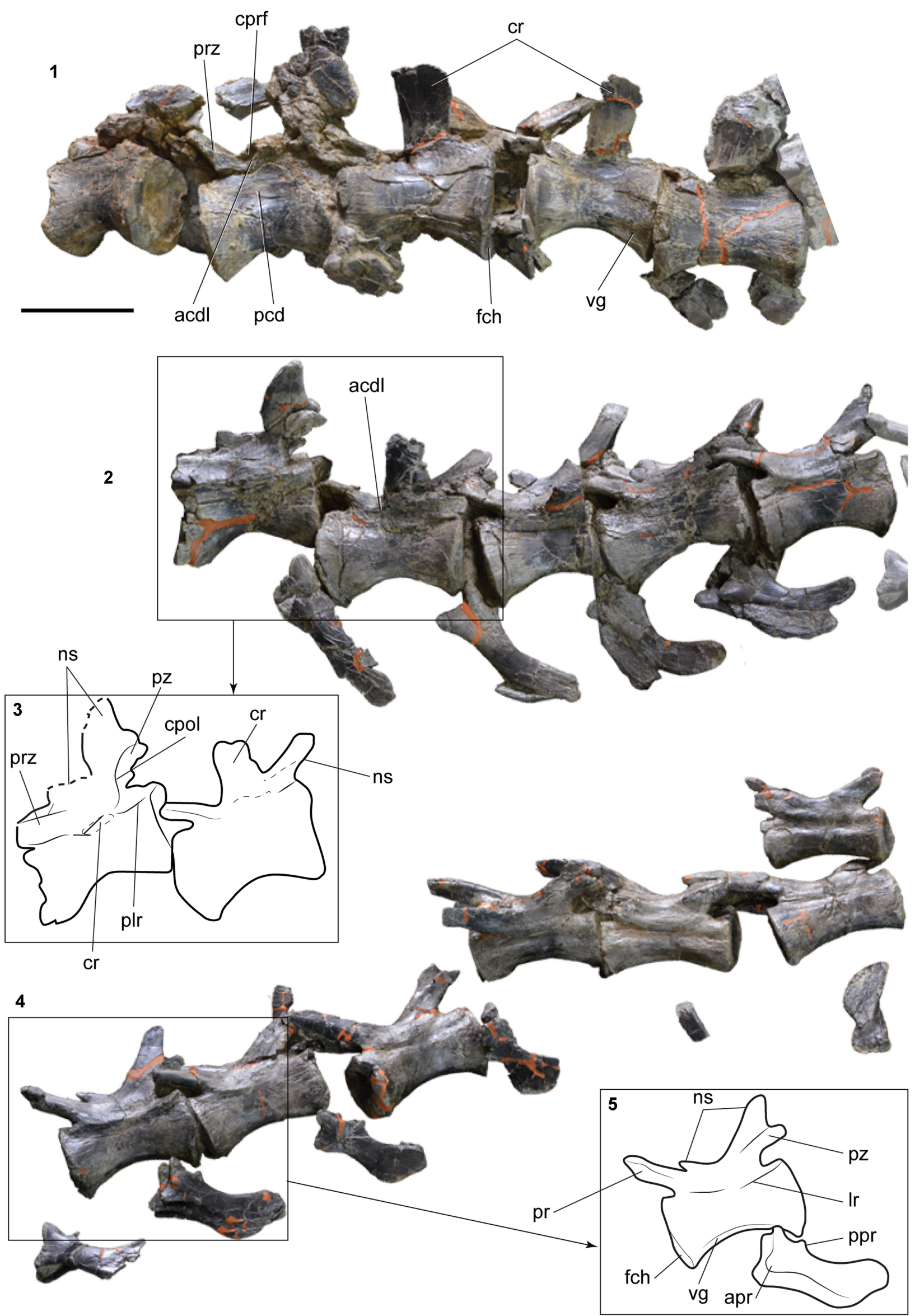

Figure 4. Details of different segments of the caudal sequence of SHN.019. (1, 2, 4) Detail of the tail segments marked in Figure 3; $(3,5)$ line drawing interpretation of some caudal vertebrae. Abbreviations: acdl, anterior centrodiapophyseal lamina; apr, anterior process; cpol, centropostzygapophyseal lamina; cprf, centroprezygapophyseal fossa; cr, caudal rib; fch, facet for chevron; lr, lateral ridge; ns, neural spine; pcd, pleurocentral depression; plr, posterior lateral

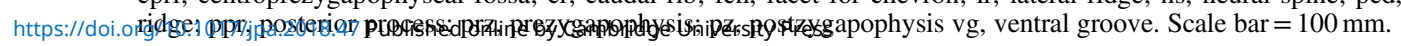


caudal vertebra, the cpol connects with the posterior surface of the caudal rib, forming a well-developed longitudinal and uninterrupted lamina.

The caudal ribs of the anteriormost caudal vertebrae are fan-shaped and slightly expanded anteroposteriorly towards the distal end. These processes project from the dorsal surface of the centrum at approximately the mid-length. Despite being somewhat fractured and distorted, it seems that the caudal ribs project laterally with an almost horizontal position. A short lamina that corresponds to the anterior centrodiapophyseal lamina (acdl) is visible at the base of the ventral surface of the caudal ribs, delimiting a shallow centrodiapophyseal fossa (cprf) adjacent to the anterior margin of the rib.

A conspicuous lateral ridge arises from the dorsal surface of the centrum in several vertebrae. This longitudinal ridge is more evident in the vertebrae posterior to the sixth caudal of the preserved series and is especially well developed in the ninth to eleventh vertebrae, but disappears in the posteriormost elements. The lateral ridge is higher adjacent to the posterior articular facet, but an anterior lower ridge is also present in these vertebrae.

Chevrons.-Markedly complete chevrons were recovered near its original position in the tail from the intervertebral position between the second and third to the $16^{\text {th }}$ and $17^{\text {th }}$ preserved caudal vertebrae. The chevrons located in the intervertebral position seventh-eighth and eighth-ninth of the preserved caudal vertebrae have almost straight shafts and slightly taper distally. Towards the posterior tip of the tail they become more curved and the distal end is slightly expanded anteroposteriorly. The morphology of the posteriormost chevrons corresponds to those commonly described as hatchet-shaped, with strongly expanded anteroposteriorly distal margins. All preserved chevrons have well-developed anterior processes and additional, spur-shaped posterior processes projecting posterodorsally (Fig. 4.4, 4.5).

Femur.-The femur is represented by a fragment of the proximal part and a fragment of the diaphysis (Fig. 5). The proximal fragment has the lesser and greater trochanters partially preserved. The lesser trochanter is broken distally and anteriorly, but the preserved fragment suggests that it would have been broad and robust. This trochanter has an aliform shape and is separated from the greater trochanter by a notch in lateral view, and from the femoral diaphysis by a broad concavity, in medial view. The anteromedial surface of the proximal part of the femur has a large foramen that pierces the base of the lesser trochanter (Fig. 5.2). The lateral surface of the lesser trochanter is slightly convex and shows a low vertical ridge extending along the midlength of the trochanter (Fig. 5.5). The lateral surface of the lesser trochanter is also ornamented by a series of thin vertical grooves and ridges mainly adjacent to the posterior margin.

The fragment of the diaphysis preserves the fourth trochanter, which is represented by a robust crest extending proximodistally along the posteromedial surface of the femur. This trochanter is distally higher and becomes lower proximally to gradually merge with the femoral diaphysis. The fourth trochanter shows a strongly striated lateral surface due to the presence of well-marked crests and grooves extending
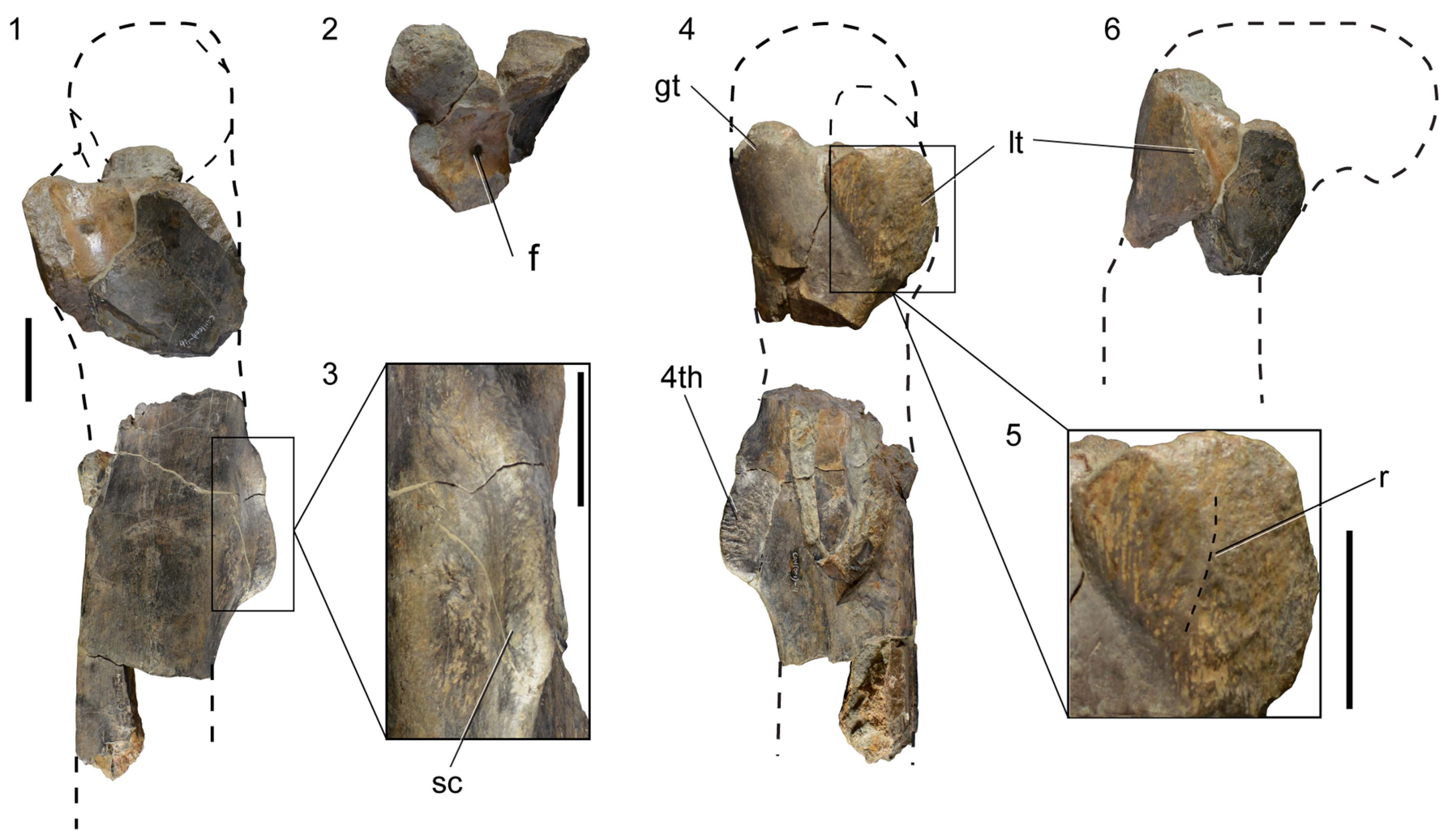

3

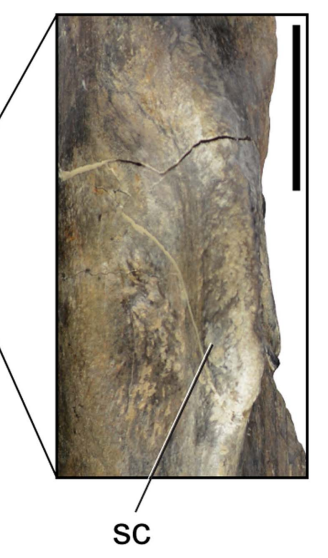

1

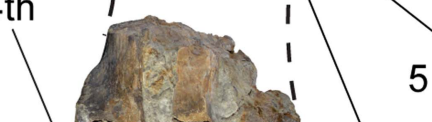

5

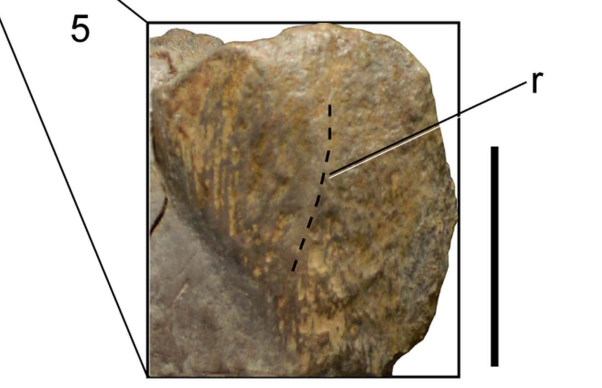

Figure 5. Fragments of a right femur of SHN.019 in medial (1), lateral (4), and posterior (6) views; (2) fragment of the proximal end in dorsal view; (3) detail of the fourth trochanter showing the deep and rough concavity in the posterior surface of the diaphysis adjacent to the trochanter; (5) detail of the lesser trochanter showing the vertical ridge on the lateral surface. The dashed lines correspond to interpretation for the missing parts based on other allosauroid specimens. Abbreviations: f, foramen; gt, greater trochanter; lt, lesser trochanter; 4th, fourth trochanter; r, ridge; sc, scar. Scale bars $=50 \mathrm{~mm}$. 
anteroposteriorly. In addition, a shallow and rugose concavity is visible in the medial surface of the femur, adjacent to the proximal part of the fourth trochanter, and a second smaller depression adjacent to the distal part of the trochanter (Fig. 5.3). The first concavity is approximately circular, whereas the latter is more oval and is bounded laterally by a well-developed crest. Distally to the fourth trochanter, the femoral diaphysis is circular in cross-section.

Tibia.-The tibia is represented by a fragment of the midsection of the diaphysis (Fig. 6.1, 6.2). This fragment is too incomplete to allow a more accurate description of the element, it being only possible to verify that the diaphysis has a crescentshaped cross-section with a flat anterior surface, as is typical in theropods.

Fibula.-The fibula preserves a fragment of the mid-section of the diaphysis and a fragment of the distal end (Fig. 6.3-6.5). This element is interpreted as a left fibula based on the position of the proximal tubercle, corresponding to the insertion of the iliofibularis muscle. This insertion does not form a real tubercle, but is a poorly defined, slightly roughened surface that extends proximodistally along the anterior margin of the fibular diaphysis. The medial surface of the fibula is strongly concave along almost the entire preserved fragment. This concavity is broad proximally, but gradually tapers distally, ending above the distal margin of the fibula. The lateral surface of the fibula is strongly convex and the posterior surface is almost flat.

The fragment of the distal part is oval in distal view and the distal surface is almost flat. The lateral surface has a series of deep vertical grooves extending adjacent to the distal margin. The lateral surface is somewhat concave, whereas the medial surface is slightly convex.

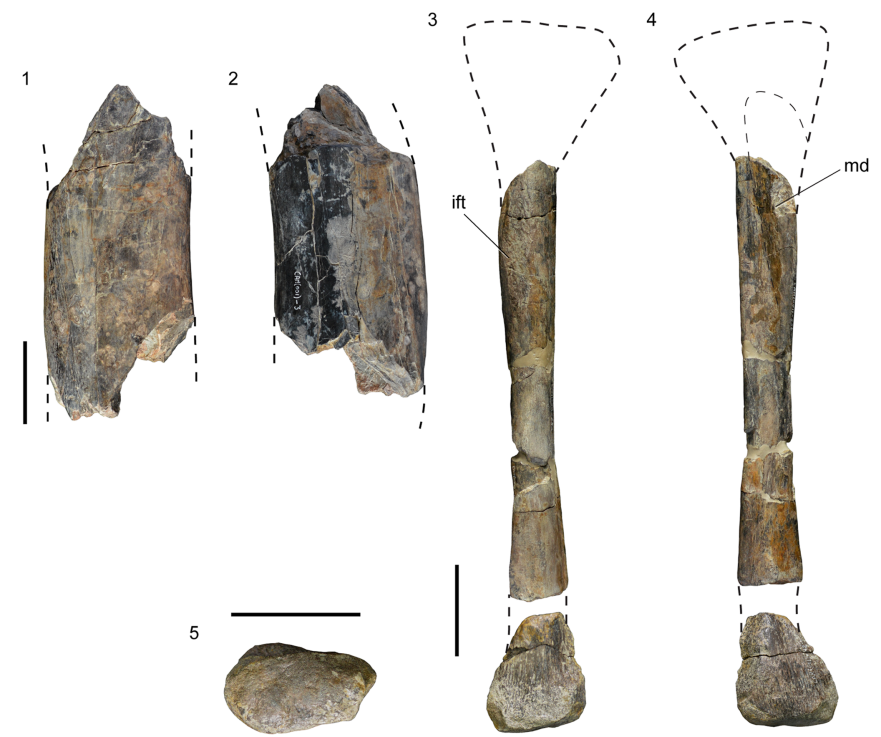

Figure 6. Fragment of the diaphysis of a tibia $(\mathbf{1}, \mathbf{2})$ and partial left fibula (3-5) of SHN.019 in lateral (1), medial (2), posterior (3), anterior (4), and distal (5) views. The dashed lines correspond to interpretation for the missing parts based on other allosauroid specimens. Abbreviations: ift, iliofibularis tubercle; md, medial depression. Scale bars $=50 \mathrm{~mm}$.
Tarsals. - The tarsals are represented by a complete and wellpreserved left calcaneum, a right tarsal IV and a fragment interpreted as a tarsal III (Fig. 7).

The calcaneum has a transversely compressed and crescent shape (Fig. 7.1-7.6). In lateral view, the calcaneum has a shallow, somewhat roughened concavity that occupies almost the entire lateral surface. The anterior surface is transversely convex and smooth with a sigmoid medial margin. In anterior view, the calcaneum slightly tapers dorsally and has a broad, shallow concavity extending laterodorsally in the proximal part of the calcaneum, which represents the facet for articulation with the distal margin of the fibula. The medial surface of the calcaneum is concave along its entire height and has a deep pit in the distal part, which would receive the lateral tuberosity of the astragalus. Despite this element being well preserved, it shows some collapsed areas, especially in the distal part, so it is not clear if the facet for insertion with the astragalus has a single pit or if this would be subdivided into two smaller pits, as occur in Allosaurus (Madsen, 1976 ).

Tarsal IV is rectangular in proximal view, slightly wider in the anterior part than in the posterior one (Fig. 7.9-7.14). It has a broadly concave proximal surface and an almost flat distal margin. The lateral surface has two deep pits, whereas the medial one is transversely convex and does not bear evidence for the presence of a pit, which is contrary to the condition described in Allosaurus (Madsen, 1976).

A fragment interpreted as belonging to a tarsal III was also recovered, but it is too incomplete to allow any informative description (Fig. 7.7, 7.8).

Pes.-The right pes is almost complete and well preserved (Figs. 8-10). All phalanges of the four digits are preserved and there are five partially preserved metatarsals. Metatarsals I and $\mathrm{V}$ are almost complete and are much shorter than the other metatarsals. Metatarsal II is broken proximally so its proximal part is unknown. Metatarsal III preserves a fragment of the midsection of the shaft and the distal end, but the proximal part is missing. Metatarsal IV is almost complete and well preserved. The length of the metatarsals was estimated based on the relative positions of the preserved fragments when the foot was found and on the morphology of more complete metatarsals of other allosauroids. The second and fourth metatarsals have approximately the same estimated length $(326 \mathrm{~mm})$ and are nearly $87 \%$ the estimated length of the third metatarsal (see Supplementary Data 3). Generally the foot is comparable to those of Allosaurus, Neovenator, and other basal avetheropods. The length of the metatarsus is $\sim 80 \%$ the length of those for Sinraptor (Currie and Zhao, 1993) and Acrocanthosaurus (Currie and Carpenter, 2000), but slightly longer and much more slender than those for Torvosaurus (Hanson and Makovicky, 2013). In addition, in Acrocathosaurus (NCSM 14345) the digit I is significantly smaller, its length being only $64 \%$ the length of that in the specimen from Cambelas. On the contrary, digit III is $\sim 66 \%$ longer in Acrocanthosaurus (Currie and Carpenter, 2000). Metatarsal V is also relatively large in SHN.019, being nearly $28 \%$ the length of the third metatarsal, whereas in Sinraptor and Allosaurus it is only 16\% (Currie and Zhao, 1993). In Torvosaurus, the second metatarsal is nearly $7 \%$ larger than 

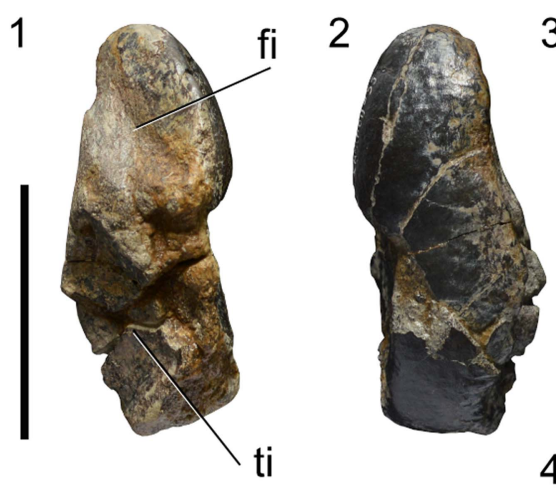

3

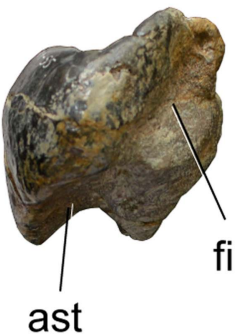

4
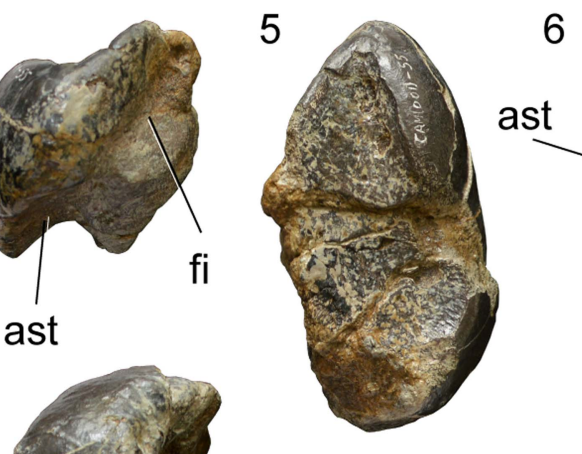
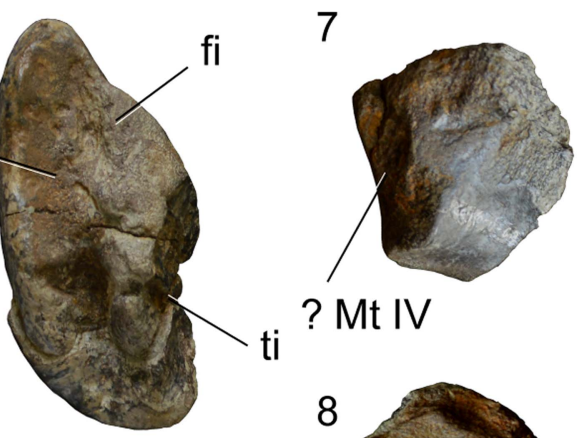

? Mt IV

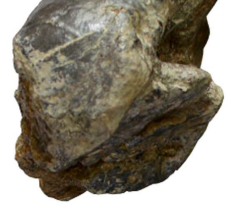

Mt IV

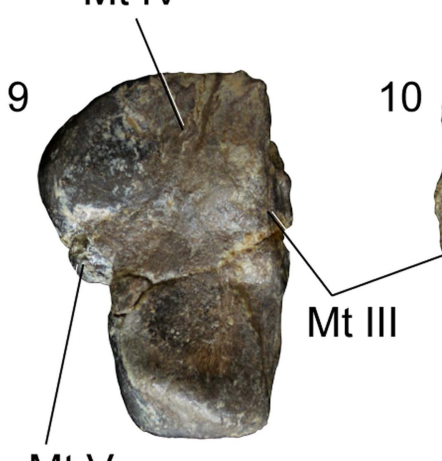

Mt V

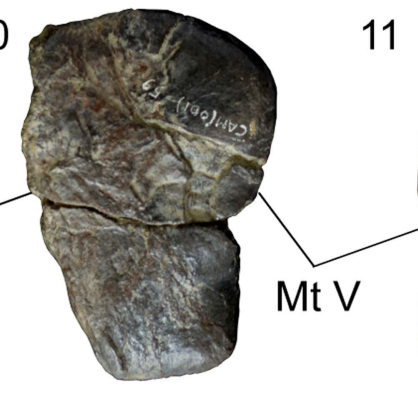

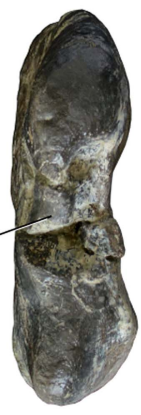

$\mathrm{t}$ III
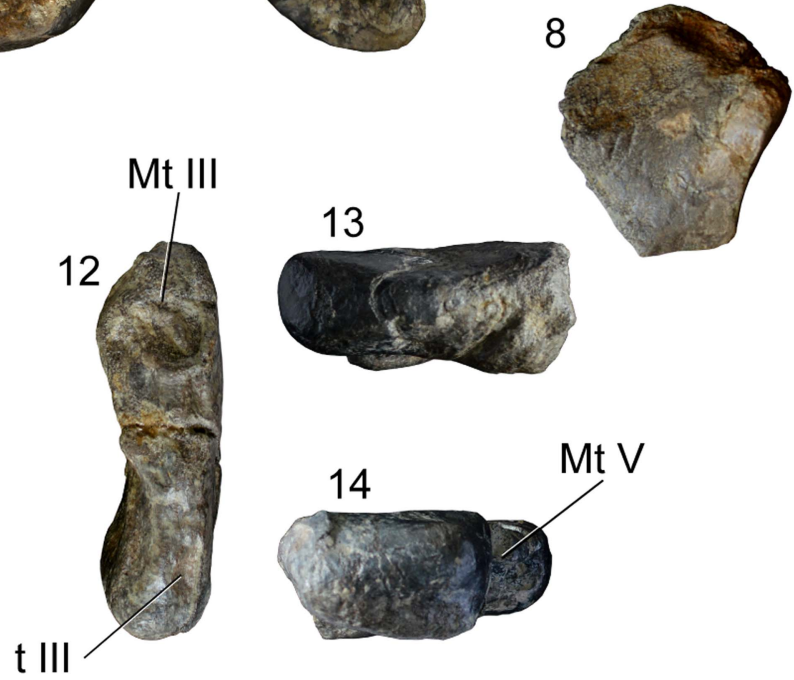

Figure 7. Proximal tarsals of SHN.019. (1-6) Left calcaneum in proximal (1), distal (2), anterior (3), posterior (4), lateral (5), and medial (6) views; (7, 8), fragment of a ?tarsal III in ventral (7) and dorsal (8) views; (9-14), right tarsal IV in distal (9), proximal (10), lateral (11), medial (12), posterior (13), and anterior (14) views. Abbreviations: ast, surface for articulation with the astragalus; fi, surface for articulation with the fibula; Mt III, Mt IV, Mt V, surface for articulation with metatarsal III, IV, and V; $\mathrm{t}$ III, surface for articulation with distal tarsal III; ti, surface for articulation with the tibia. Scale bar $=50 \mathrm{~mm}$.

the fourth and $\sim 86 \%$ the length of the third (Hanson and Makovicky, 2013).

Metatarsal I is a proximodistally short, but relatively robust element that tapers proximally and is triangular in proximal view, with the shaft being strongly compressed transversely above the distal condyles. The distal part has a ball-shaped morphology with a large and rounded anterior condyle and two well-developed condyles separated by a deep flexor groove in posterior view. This morphology of the distal articular facet would allow a wide movement and position range for the first digit (Fowler et al., 2011). The flexor groove connects with a shallow concavity on the posterior surface of the distal margin of the metatarsal. The distal end projects slightly anteriorly, but is mostly parallel to the shaft. In distal view, the condyles are circular and strongly convex transversely. The medial condyle has a ridge extending posteromedially well beyond the level of the posterior margin of the lateral condyle (Fig. 9.2). The lateral collateral ligament pit is shallow and poorly defined, contrasting with the deep and proximodistally elongated medial pit. The shaft shows a slightly rough area extending along the medial and posterior surfaces, which is interpreted as the surface for articulation with metatarsal II. Metatarsal I was probably tied by ligaments to the mid-shaft of metatarsal II and did not reach the tarsus, as occurs in most theropods (Rauhut, 2003b; Galton et al., 2015).

Metatarsal II is a robust and moderately large element (see Supplementary Data 3). It is broken at approximately the midlength of the shaft and the proximal part is missing. The distal margin has two well-developed and rounded condyles, which are separated by a deep flexor groove on the posterior surface and by a shallow groove extending anteroposteriorly on the distal surface. The lateral condyle is oval, with the long axis oriented anteroposteriorly, and is slightly larger than the medial one. Deep and well-delimited lateral and medial collateral ligament pits are visible and the medial pit is slightly deeper than the lateral one. The shaft is rectangular in dorsal view, with a flat anterior surface, a slightly convex posterior border, and almost parallel lateral and medial margins. The posterior margin of the shaft shows a flattened oval surface extending proximally from nearly $78 \mathrm{~mm}$ above the distal condyles. This surface is interpreted as the area for attachment with metatarsal III. The medial surface of the shaft is somewhat concave in anterior view.

Metatarsal III is very incomplete and distorted, but preserves a fragment of the mid-section of the shaft and the distal end. The preserved fragment of the shaft does not show evidence for a proximal constriction of this metatarsal, which is the arctometatarsalian condition that characterizes several coelurosaurian theropods, including ornithomimids, troodontids, caenagnathids, and tyrannosaurids (Currie, 2000). In anterior view, the shaft seems to have a pronounced curvature, being concave medially and convex laterally, but this feature may be in part due to taphonomic deformation. The medial surface is somewhat flat, especially the distal part of the preserved fragment. This flattened area probably corresponds to the surface for attachment with metatarsal IV. The distal end is 
1

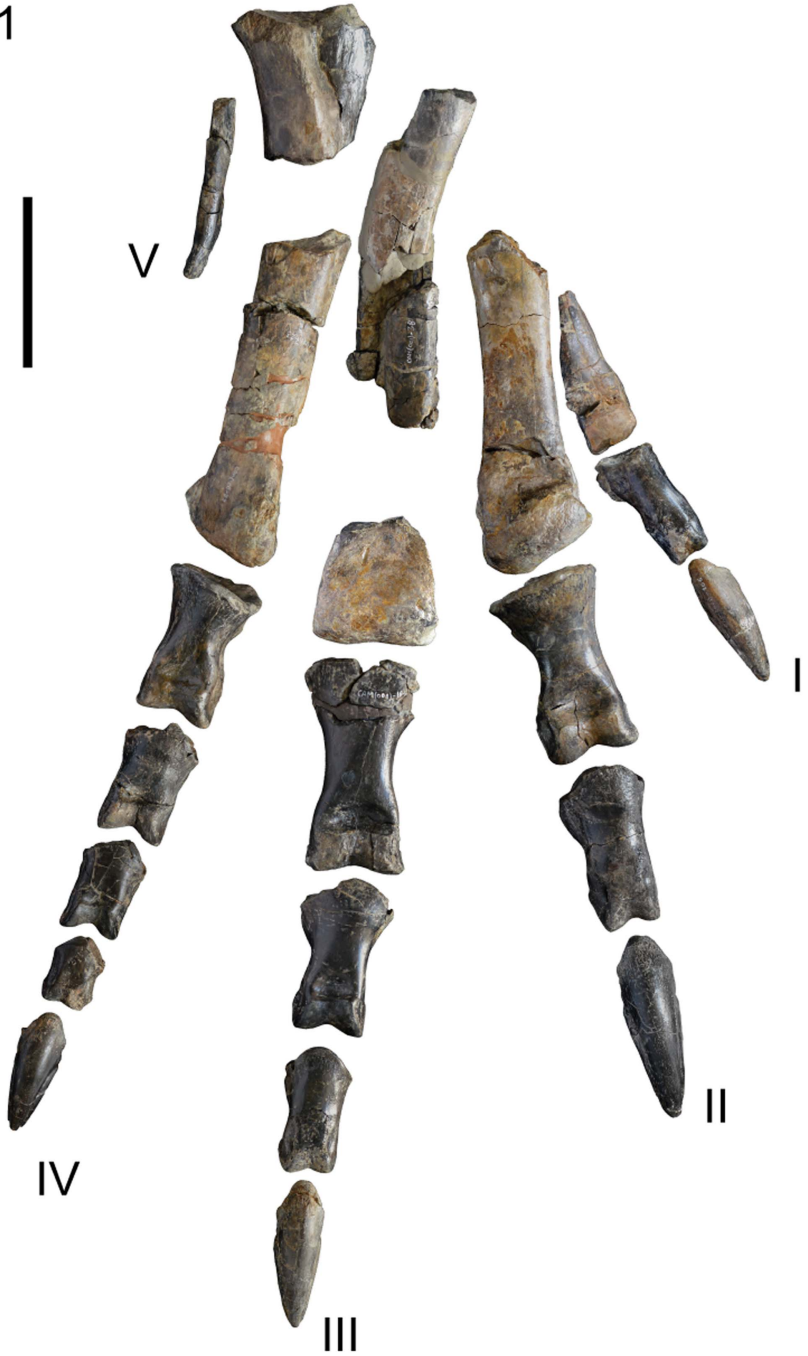

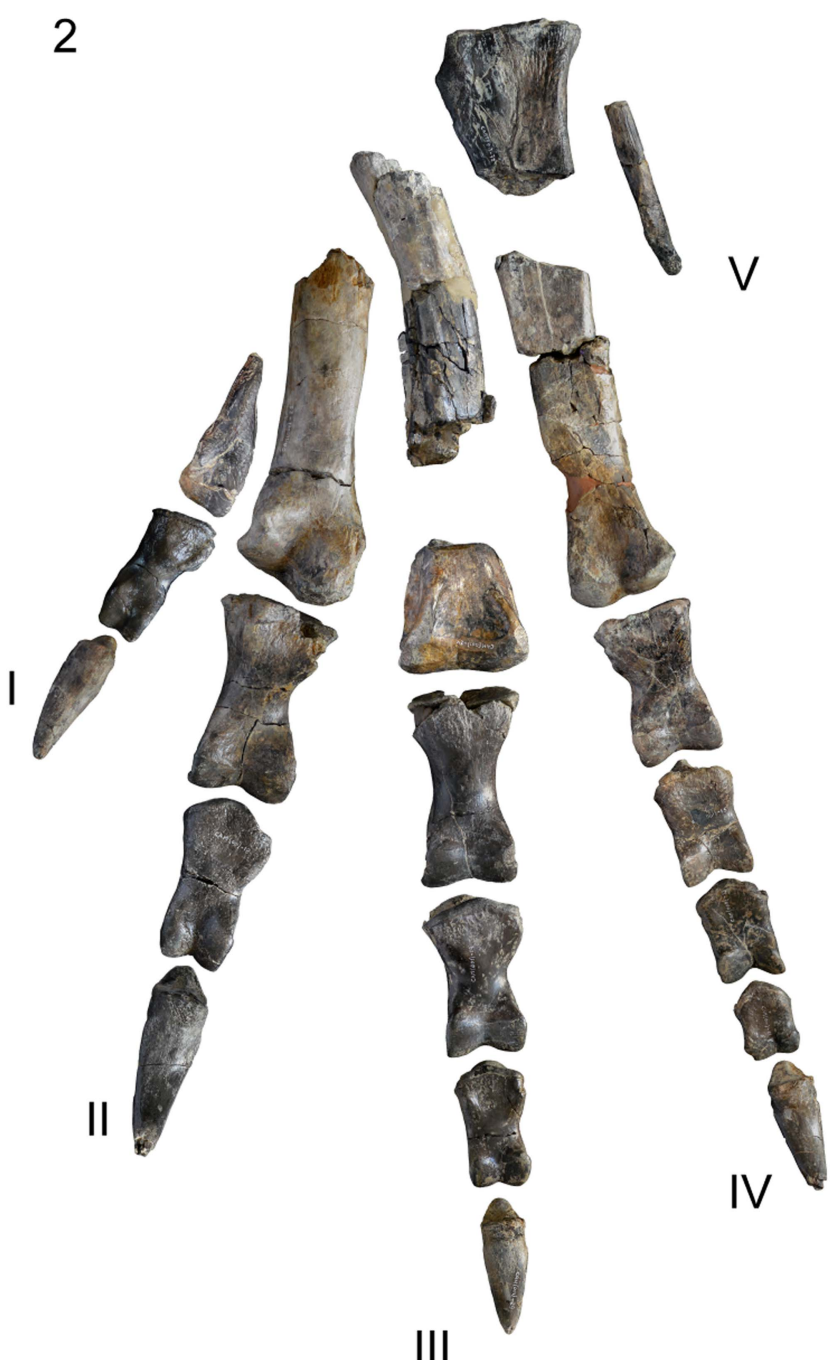

III

Figure 8. Right pes of SHN.019 in anterior (1) and posterior (2) views. Scale bar $=100 \mathrm{~mm}$.

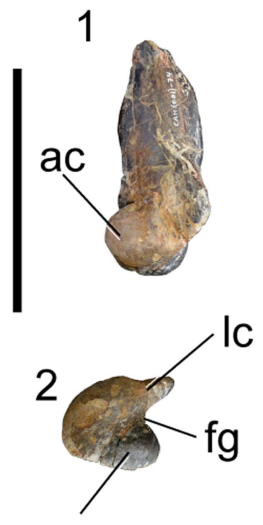

$\mathrm{mc}$
3

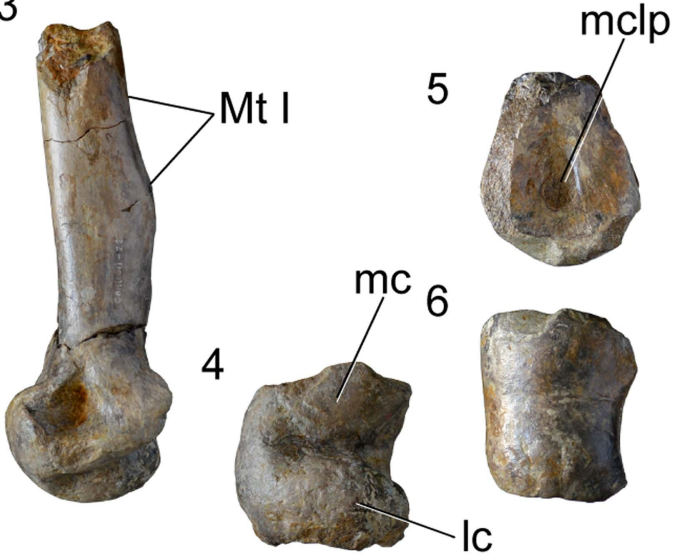

7

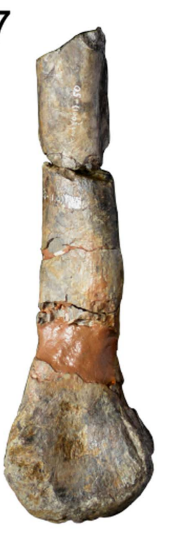

8
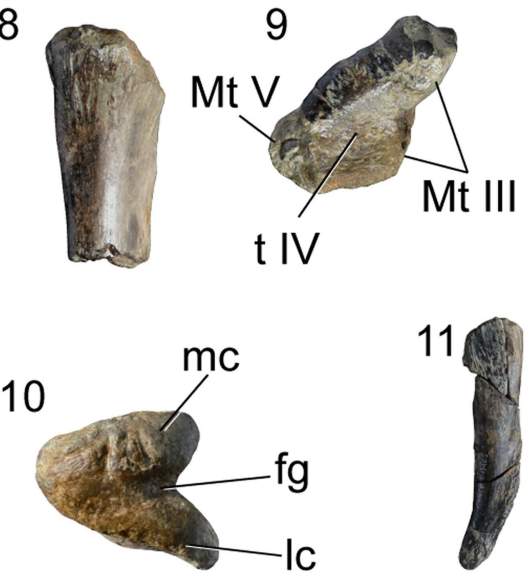

Figure 9. Metatarsals preserved of the right pes of SHN.039. (1, 2) Metatarsal I; (3, 4) metatarsal II; (5, 6) metatarsal III; (7-10) metatarsal IV; and (11) metatarsal V in anterolateral $(\mathbf{1})$, distal $(\mathbf{2}, \mathbf{4}, \mathbf{6}, \mathbf{1 0})$, left lateral $(\mathbf{3}, \mathbf{5}, \mathbf{7}, \mathbf{8}, \mathbf{1 1})$, and proximal $(\mathbf{9})$ views. Abbreviations: ac, anterior condyle; fg, flexor groove; lc, lateral condyle; mc, medial condyle; mclp, medial collateral ligament pit; Mt I, Mt III, Mt V, surface for articulation with metatarsal I, III, V. t IV, surface for articulation with distal tarsal IV. Scale bar $=100 \mathrm{~mm}$.

robust, rectangular in distal view, and transversely convex, with poorly defined condyles, which are separated by a shallow groove in the distal surface. A shallow concavity is visible in the anterior surface above the most-proximal margin of the distal articular surface. The distal condyles project mostly distally, not anterodistally, as in metatarsals I and II. The posterior surface 
has two low and parallel ridges extending from the distal condyles. Deep and circular collateral ligament pits are visible in both medial and lateral surfaces, with the lateral pit slightly shallower than the medial one.

Metatarsal IV is almost complete and well preserved, lacking a fragment of the mid-section of the shaft. The shaft is crescent-shaped in cross-section, with a flat medial surface along almost the entire length. The distal end has two welldeveloped condyles, which are separated on the posterior surface by a deep flexor groove. The distal articular facet is triangular in distal view. The condyles are separated at the posterior margin by a deep flexor groove extending to the distal border of the articular surface. The medial condyle is oval, projects anteroposteriorly, and is slightly larger than the medial condyle. On the other hand, the lateral condyle has a ridge-shape and projects posteromedially well beyond the level of the posterior margin of the medial condyle (Fig. 9.10). Only the medial collateral ligament pit is perceptible, but it is shallow and poorly preserved. The shaft strongly expands proximally and the proximal margin is two times longer anteroposteriorly than transversely (see Supplementary Data 3). The proximal surface is concave and slightly tapers to the posterior part. The medial surface of the proximal margin has a deep concavity extending distally from the proximal border of the posteromedial surface of the shaft, and that is bounded at the anterior part by a sharp longitudinal crest. This concavity is interpreted as the surface for articulation with metatarsal III.

Metatarsal $\mathrm{V}$ is broken proximally and the proximal part is absent. This element is reduced and consists of a thin, transversely flattened shaft tapering distally and slightly bowed anteriorly. The shaft has a flat medial surface, possibly for articulation with metatarsal IV, and a rough dorsal surface.

SHN.019 preserves all phalanges of the right pes. The third digit is the longest, with a total length of the phalanges $\sim 330 \mathrm{~mm}$, and the second and fourth digits have almost the same length (see Supplementary Data 3). The phalanges are relatively slender and longer than wide. All non-ungual phalanges have well-developed distal condyles and almost symmetrical distal margins, except phalanges 1-I and 2-II, in which they are somewhat asymmetrical (the medial condyle is slightly more posteriorly projected than the lateral one). The proximal articular facets of all phalanges are slightly concave and generally with a circular contour, except the ungual phalanges, which have oval proximal margins that are anteroposteriorly longer than transversely wide (Fig. 10). Lateral and medial collateral ligament pits are well marked in all non-ungual phalanges. The lateral pit is slightly shallower than the medial one in most phalanges of digits I, II, and III (except in the phalanx 1-III and 2-III, in which the lateral and medial pits are almost equally developed), but in the phalanges of digit IV, the lateral pit is deeper than the medial one. A shallow concavity is visible in the anterior surface above the distal condyles in most non-ungual phalanges, except in the penultimate phalanges of each digit. This concavity is much developed and well marked in phalanges 1-II and 1-III, in which it occupies almost the entire transverse width of the distal end.

Phalanges 1-II and 1-III are the most robust of all phalanges (see Supplementary Data 3). These elements have the proximal and distal ends strongly offset from the shaft, which gives a somewhat constricted appearance to the phalanx. This morphology is also observable in phalanges 2-III and 1-IV, whereas the other non-ungual phalanges have straighter shafts. Phalanges 2, 3 , and 4 of digit IV are rectangular in contour, with subparallel medial and lateral margins. The posterior surface of phalanges 1-I, 1-II, and 1-III has slightly concave and rough areas adjacent to the proximal end. In phalanx 1-II, this rough area is delimited by well-developed medial and lateral ridges. On the contrary, phalanx 2-II has an almost flat posterior surface.

In lateral view, the ungual phalanges are strongly arched, concave ventrally, and convex dorsally (Fig. 10). They have triangular cross-sections with an almost flat ventral surface, which is transversely wider than the dorsal surface. The ungual phalanx of digit II is the largest of all unguals, whereas the ungual of digit I is slightly larger than the ungual of digit IV, but smaller than those of digits II and III (see Supplementary Data 3). A pair of longitudinal grooves extends near the mid-height of both lateral and medial surfaces in all ungual phalanges. These grooves extend from the ventral margin of the proximal end to the distal tip of the phalanx. The lateral groove is slightly shallower than the medial one. The proximal margin of the ungual phalanges has an anteroposteriorly oriented ridge that subdivides the articular facet in two concavities for articulation with the distal condyles of the previous phalanx. The proximal articular facets of most non-ungual phalanges, except in the first phalanges of digits I to IV, also have similar ridges. The anterior margin of the proximal part of the ungual phalanges extends more proximally than the ventral margin, forming a blunted anterior process.

Remarks.-The specimen from Cambelas, SHN.019, is identifiable as a tetanuran theropod based on the proximal position of the femoral lesser trochanter (Pérez-Moreno et al., 1993; Benson, 2010). In addition, it also shares with Orionides the following set of features: (1) anterior spur-shaped process in the neural spine of mid-caudal vertebrae (Rauhut, 2003b; Benson, 2010); (2) distal caudal vertebrae with strongly elongated prezygapophyses, overhanging at least one-quarter of the length of the preceding centra (Rauhut, 2003b); (3) distal end of metatarsal IV deeper than broad (Carrano and Sampson, 2008; Carrano et al., 2012); (4) reduced length of metatarsal I, $<50 \%$ of metatarsal II (Carrano et al., 2012); and (5) metatarsal I with broadly triangular shaft, and distally placed (Rauhut, 2003b). Within Orionides, SHN.019 shares with avetheropods the morphology of the shaft of the metatarsal III with a wedge shaped cross-section, which is a feature considered a synapomorphy for this clade (Benson, 2010; Carrano et al., 2012).

SHN.019 differs from coelurosaurs and some derived carcharodontosaurids (e.g., Giganotosaurus and Mapusaurus) by having a well-developed, semi-oval, flange-shaped fourth trochanter of the femur (Coria and Currie, 2006; Brusatte et al., 2008; Benson, 2010). Also, the pes does not show the strong constriction of the third metatarsal that is typical for most coelurosaurian theropods (e.g., Currie, 2000; Brochu, 2003). The specimen shares with some ceratosaurians, Lourinhanosaurus, some methriacantosaurids, Concavenator, and some coelurosaurians the tapered distal end of mid-anterior chevrons (Benson, 2010; Ortega et al., 2010; Carrano et al., 2012). However, the posteriorly inclined neural spines of mid-caudal 


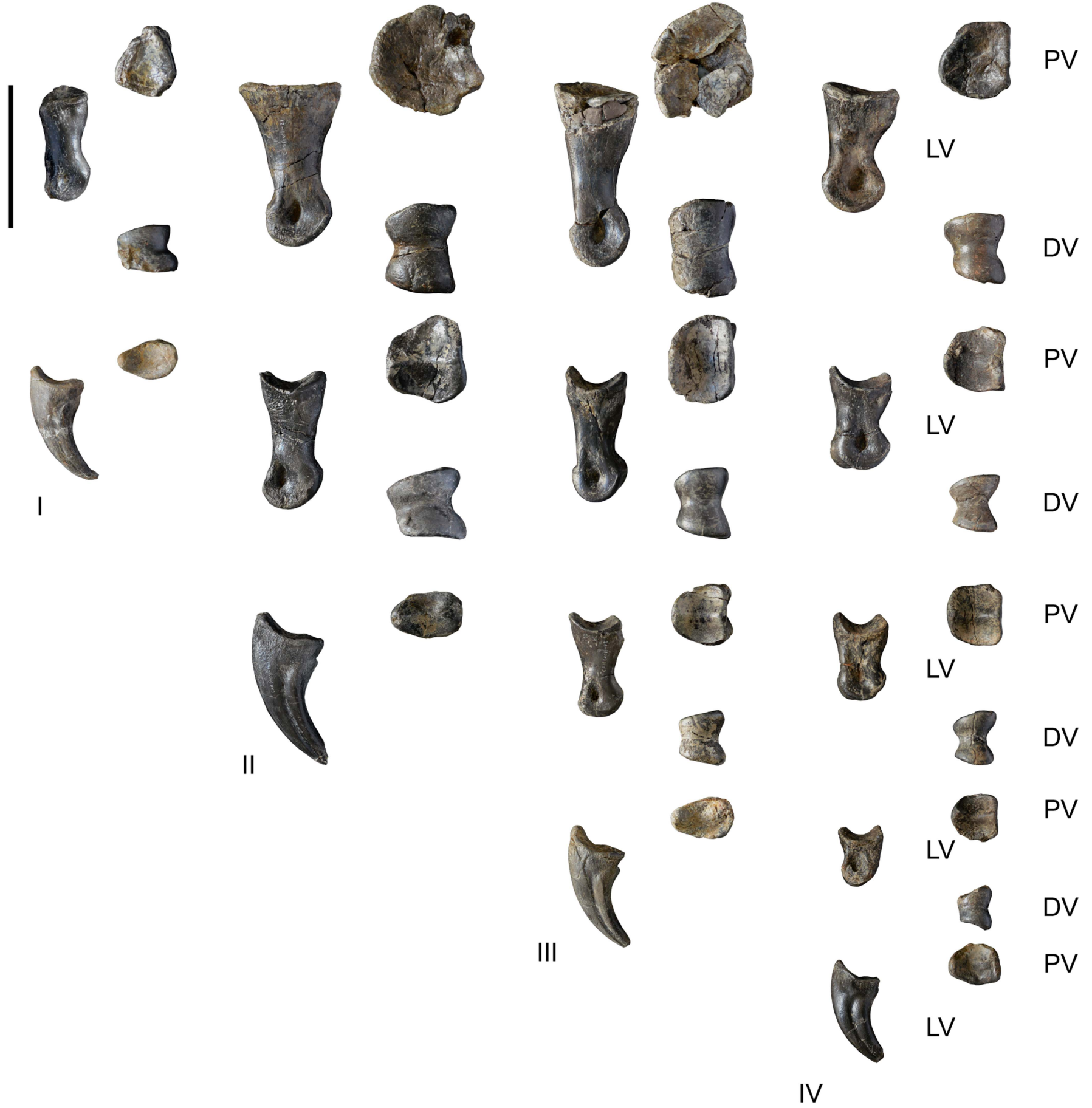

Figure 10. Phalanges of the right pes of SHN.019. Legend: PV, proximal view; LV, left lateral view; DV, distal view. Scale bar $=100 \mathrm{~mm}$.

vertebrae contrast with the vertical or even slightly inclined anteriorly spines of most ceratosaurians, including Ceratosaurus and abelisaurids (Rauhut, 2003b).

Late Jurassic tetanuran theropods currently known in the Portuguese record include the megalosaurid Torvosaurus, the allosauroids Allosaurus and Lourinhanosaurus, and the tyrannosauroid Aviatyrannis, together with a variety of other possible coelurosaurs with uncertain identification (e.g., Mateus, 1998; Zinke, 1998; Pérez-Moreno et al., 1999; Rauhut, 2003a; Mateus et al., 2006; Hendrickx and Mateus, 2014b). Torvosaurus is represented by some cranial, axial, and appendicular elements that cannot be compared with the available material of SHN.019. However, as discussed above, the specimen herein described shares several features with avetheropod tetanurans and may be assigned with confidence as belonging to this clade.

Allosaurus is currently the most abundant and wellrepresented theropod taxon in the Upper Jurassic of the 
Lusitanian Basin. SHN.019 shows some similarities with Allosaurus, but differs from this taxon in several details, including: (1) caudal neural spines still well developed at least up to the thirty-first caudal vertebra, whereas they disappear at about the twenty-eight caudal in Allosaurus (Gilmore, 1920; Madsen, 1976); (2) distal surface of metatarsal II almost flat, with a much shallower groove separating the condyles; and (3) morphology of the distal end of metatarsal IV with the lateral condyle extending farther posteriorly than the medial process and being wing-shaped.

Lourinhanosaurus antunesi Mateus, 1998 was based on a partial skeleton (ML 370) collected in Peralta (Lourinhã, Portugal) that includes cervical, dorsal, sacral and caudal vertebrae, dorsal ribs, chevrons, an almost complete pelvic girdle, and elements of the hind limbs, including partial femora, right tibia and fibula, a fragment of a metatarsal III, and the proximal articular surface of a first phalanx of the second digit. It was originally described as an allosauroid (Mateus, 1998) and latter interpreted as a more basal tetanuran closely related with eustreptospondyline megalosaurids (Mateus, 2005; Mateus et al., 2006). Subsequently, it was recovered as a member of the basal allosauroid clade Metriacanthosauridae by Benson (2010) and as a possible coelurosaur by Carrano et al. (2012).

The overlapping available material of SHN.019 and Lourinhanosaurus is limited to a few caudal vertebrae and a partially preserved femur. The new specimen shares with this taxon the presence of a well-developed anterior centrodiapophyseal lamina (acdl) and associated prezygapophyseal centrodiapophyseal fossa (prcdf) fossa in anterior mid-caudal vertebrae and the tapered distal end of the mid chevrons (also shared with SHN.036: Malafaia et al., 2017). However, the femur of the specimen from Cambelas has a low vertical crest on the lateral surface of the lesser trochanter and a well-developed and rugose concavity in the medial surface adjacent to the proximal end of the fourth trochanter, which are absent in Lourinhanosaurus (as well as in Allosaurus). These characters were considered diagnostic for Neovenator (Brusatte et al., 2008). However, a similar ridge on the lateral surface of the lesser trochanter is also present in Acrocanthosaurus (D'Emic et al., 2012), Australovenator (Hocknull et al., 2009), and Concavenator (E. Malafaia, personal observation, 2016), suggesting a wider distribution for this feature among Carcharodontosauria.

SHN.019 has strongly developed anterior spur-shaped processes in the mid-caudal neural spines. The presence of these processes is shared by some megalosauroids, including Afrovenator (Sereno et al., 1994) and Wiehenvenator (Rauhut et al., 2016), Lourinhanosaurus (Mateus, 1998), Allosaurus (Madsen, 1976), most methriacanthosaurids (e.g., Sinraptor: Currie and Zhao, 1993 and Siamotyrannus: Buffetaut et al., 1996), and most carcharodontosaurs, including Concavenator (Ortega et al., 2010), Acrocanthosaurus (Currie and Carpenter, 2000), and Mapusaurus (Coria and Currie, 2006). However, in these taxa the additional anterior process of the caudal neural spines is not as developed as in Lourinhanosaurus, and this feature was considered one of the autapomorphies for this taxon (Mateus, 1998). The preserved caudal vertebrae of Lourinhanosaurus consist of two sequences from the anterior and midsection of the tail. Caudal vertebrae of corresponding position are not preserved or have broken neural spines in SHN.019, so direct comparison between the two specimens is not possible. However, some mid-posterior caudal vertebrae of SHN.019 preserve well-developed processes, larger than those of correspondent caudal vertebrae in Allosaurus, but much lower and more rounded than those of Lourinhanosaurus (Fig. 11).

The femur of SHN.019 is incomplete and it is not possible to verify the presence of a nutrient foramen in the anteromedial surface at the base of the lesser trochanter, as is present in Allosaurus, Neovenator, and most other theropods (e.g., Madsen, 1976; Brusatte et al., 2008). On the other hand, SHN.019 has a foramen between the lesser trochanter and the femoral diaphysis on the medial surface of the proximal end. If this foramen corresponds to the principal nutrient foramen, its position is unusual for theropods.

SHN.019 shares with a previously described specimen, SHN.036, collected from upper Kimmeridgian strata of the Praia da Amoreira-Porto Novo Formation, an unusual feature in the mid-posterior caudal vertebrae, a strongly developed lateral

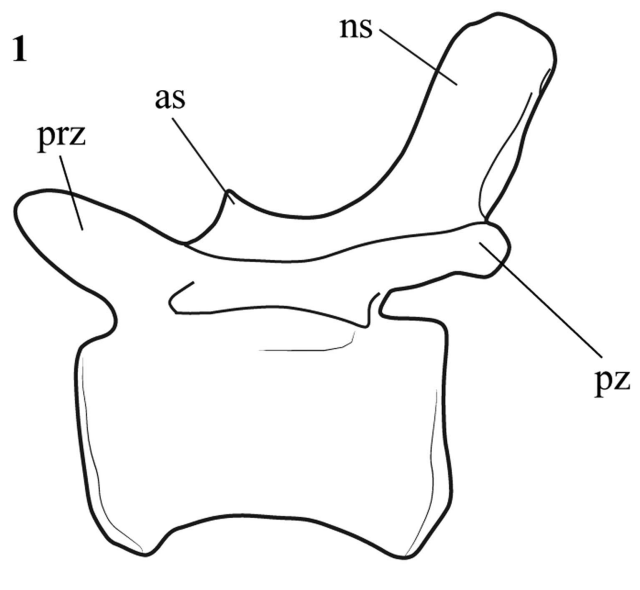

2

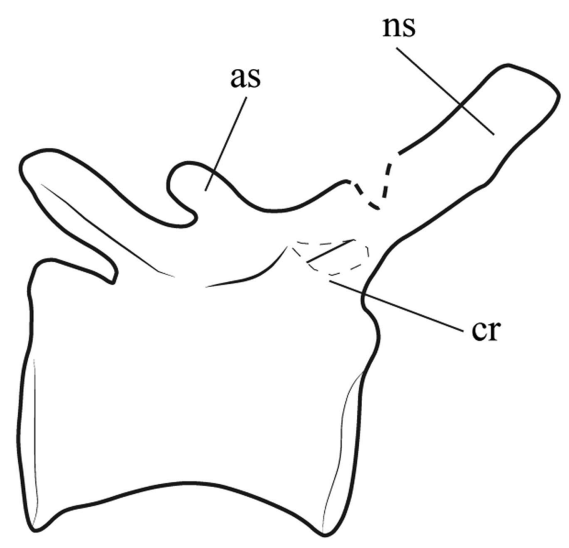

3

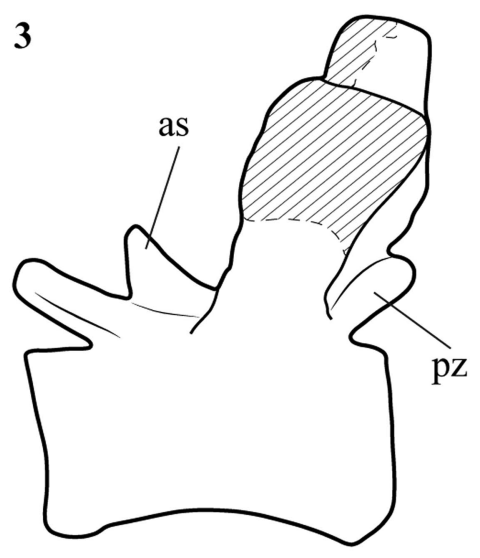

Figure 11. Line drawing of mid caudal vertebrae in left lateral view of (1) Allosaurus (nineteen caudal vertebrae; after Madsen, 1976); (2) SHN.019 (nineteen or twenty caudal vertebrae); and (3) Lourinhanosaurus (anterior mid-caudal vertebrae; after Mateus, 1988). Abbreviations: as, anterior spur; cr, caudal rib; ns, neural spine; prz, prezygapophysis; pz, postzygapophysis;. Scale bars $=50 \mathrm{~mm}$. 
lamina projecting from the posterior articular facet to the base of the caudal rib. In some vertebrae, especially those near the "transition point," a lower lateral lamina extending from the base of the prezygapophysis along the anterior end of the centrum is also present. A similar anterior lateral lamina is interpreted as a synapomorphy for Carcharodontosauria (Brusatte et al., 2008) and is visible in some anterior mid-caudal vertebrae of Concavenator (E. Malafaia, personal observation, 2016) and in Veterupristisaurus (Rauhut, 2011). However, in these taxa the anterior lateral lamina is more developed than the posterior lamina, whereas the specimens from the Lusitanian Basin, SHN.019 and SHN.016, show the opposite condition. In conclusion, the morphology of the femur and the presence of a lateral lamina extending from the base of the prezygapophysis along the anterior end of the centrum in the mid-posterior caudal vertebrae suggest that SHN.019 is a member of the clade Carcharodontosauria.

\section{The presence of carcharodontosaurian theropods in the Late Jurassic of the Lusitanian Basin: paleobiogeographic implications}

The Carcharodontosauria is a diverse and widely distributed allosauroid clade more typical from Cretaceous strata of the southern hemisphere, but that is also relatively well represented in Laurasian landmasses. The earliest Cretaceous carcharodontosaurian taxa known so far are from the Barremian of Spain (Concavenator corcovatus Ortega, Escaso, and Sanz, 2010; Cuesta et al., 2015) and England (Neovenator salerii Hutt, Martill, and Barker, 1996; Brusatte et al., 2008) together with a recently reported specimen from the Valanginian of Patagonia, which was also tentatively assigned to this clade (Coria et al., 2017). The clade rapidly diversified and dispersed, attaining a near-cosmopolitan distribution at the end of the Early Cretaceous. It has been assumed that Carcharodontosauria has a ghost lineage extending back to the Late Jurassic (Brusatte et al., 2008). More recently, several isolated elements from Upper Jurassic strata in several localities have been attributed to this clade, including an isolated ilium, some caudal vertebrae, and teeth from the Tendaguru Formation (Rauhut, 2011; Carrano et al., 2012), some teeth from the Middle-Upper Jurassic Shishugou Formation of China (Han et al., 2011), and possibly some teeth from the Lower Saxony Basin of Germany (Gerke and Wings, 2016). The presence of carcharodontosaurian theropods in the Upper Jurassic of the Lusitanian Basin adds significant information to fill the gap in the knowledge of the early evolution of these theropods, extending the record of the clade already well represented in the Lower Cretaceous of Europe and other Laurasian landmasses.

The Late Jurassic theropods of the Lusitanian Basin have traditionally been interpreted as closely related to those of correlative sedimentary sequences from the North American Morrison Formation and the African Tendaguru Formation. This interpretation is based on the identification of several shared taxa, including Ceratosaurus, Torvosaurus, and Allosaurus (Pérez-Moreno et al., 1999; Antunes and Mateus, 2003; Mateus et al., 2006). The general composition of the theropod fauna from the Tendaguru Formation apparently contrasts with those of both the Morrison Formation and the Lusitanian Basin because in the latter, the theropod faunas were dominated by tetanurans and abundant coelurosaurs, whereas in the former, ceratosaur taxa are the more abundant and diverse and coelurosaurs are unknown altogether (Rauhut, 2011; Rauhut and Carrano, 2016; Malafaia et al., 2017). On the other hand, the faunal composition of theropods from the Morrison Formation and the Lusitanian Basin is very similar. Most of the genera currently known in the Portuguese record have a closely related taxon in the North American record, which has been used as evidence of faunal interchanges across the proto-North Atlantic Ocean during the Late Jurassic (e.g., Perez-Moreno et al., 1999). However, there are also a few taxa interpreted as exclusive from the Portuguese record (Lourinhanosaurus), and some taxa that are closely related to those known in North America have more recently been reinterpreted as distinct species that are exclusive to the Lusitanian Basin, including Allosaurus europaeus Mateus, Walen, and Antunes, 2006 and Torvosaurus gurneyi Hendrickx and Mateus, 2014b (Mateus et al., 2006; Hendrickx and Mateus, 2014b). This scenario suggests an incipient vicariant evolution of the Late Jurassic theropod faunas from both margins of the proto-North Atlantic Ocean.

Despite the similarity in the dinosaur faunas from the Late Jurassic of the Lusitanian Basin and the Morrison Formation, some higher taxonomic groups that apparently are absent in correlative North American strata (e.g., carcharodontosaurian theropods and turiasaurian sauropods) have been identified in the Portuguese record. These clades are instead more closely related with some Gondwanan faunas, especially those known from the North African record. These differences in the higherlevel taxonomic composition of the dinosaur faunas between the Lusitanian Basin and the Morrison Formation may indicate different patterns of regional extinction and local environmental preferences (Benson et al., 2012).

\section{Conclusion}

The specimen herein described, SHN.019, is identified as an avetheropodan tetanuran based on the morphology of metatarsal III, with a wedge-shaped cross-section of the shaft. Within this clade, SHN.019 differs from coelurosaurs in the structure of the fourth trochanter of the femur and the non-constricted third metatarsal. This combination of features allows us to identify the new specimen as an allosauroid theropod. In addition, it is tentatively related with another previously described specimen, SHN.036, based on the shared presence of a strongly developed lateral lamina in the caudal vertebrae near the "transition point." SHN.019 shows particular differences relative to other allosauroids currently known in the Upper Jurassic of Portugal, Allosaurus and Lourinhanosaurus, which indicate that it probably corresponds to a distinct taxon not yet identified in the Upper Jurassic record of the Lusitanian Basin. Some of the characters observed in the individual SHN.019, such as the morphology of the femur and the lateral lamina extending from the base of the prezygapophysis along the anterior end of the centrum in the caudal vertebra, allows considering it as a member of Carcharodontosauria. Nevertheless, there is no autapomorphic trait identifiable in the specimen that allows the diagnosis of a new taxon, and thus it is considered as an indeterminate member of Carcharodontosauria. This description 
expands the geographic distribution of Carcharodontosauria to Upper Jurassic (upper Tithonian) of Laurasia.

SHN.019 includes the most complete pes of a theropod known from the Upper Jurassic record of the Iberian Peninsula, allowing a better knowledge of the pedal morphology of these large theropod dinosaurs and comprehension of its evolution within the Allosauroidea clade. These data may also allow testing hypotheses related with the identification of the producers of some theropod tracks from the Iberian Upper Jurassic record.

SHN.019 is one of the few theropod remains known from the Turcifal Sub-basin and adds relevant information for the knowledge of the dinosaur faunas from the end of the Jurassic (upper Tithonian) in this sector of the Lusitanian Basin.

\section{Acknowledgments}

This work was supported by the Fundação para a Ciência e Tecnologia (Portugal) under a $\mathrm{PhD}$ scholarship (SFRH/BD/ 84746/2012) and by a protocol between CMTV and SHN. Individual grants to E.M. for visits for review collections were financed by the Jurassic Foundation, Fundação Luso-Americana para o Desenvolvimento (grant number L07-V-22/2010) and Synthesys (grant number GB-TAF-2160 and FR-TAF-4911). We thank to the editors, J. Kastigar and H.-D. Sues, and J.I. Canale for comments in a previous version of the manuscript, and to the reviewers R. Coria and O.W.M. Rauhut for comments and suggestions. We also thank G. Ramalheiro for preparation of some elements of SHN.019, C. Moniz and M. Cachão for comments on the paper, and to the following for access to specimens: B.C. Silva (SHN), R. Castanhinha and C. Tomás (ML), V. dos Santos (MUHNAC), R. Allain (MNHN), L. Chiappe (NHMLAC), K. Carpenter (DMNS), R. Scheetz and B. Britt (BYU), M. Getty, M. Loewen, and R. Irmis (NHMU), D. Chure (DINO), S. Chapman (NHMUK), P. Jeffery (OUMNH), and T. Schossleitner and D. Schwarz (MfN).

\section{Accessibility of supplemental data}

Data available from the Dryad Digital Repository: http://doi. org/10.5061/dryad.40655hr

\section{References}

Antunes, M.T., and Mateus, O., 2003, Dinosaurs of Portugal: Comptes Rendus Paleovol, v. 2, p. 77-95.

Araújo, R., Castanhinha, R., Martins, R.M.S., Mateus, O., Hendrickx, C., Beckmann, F., Schell, N., and Alves, L.C., 2013, Filling the gaps of dinosaur eggshell phylogeny: Late Jurassic theropod clutch with embryos from Portugal: Scientific Reports, v. 3, doi:10.1038/srep01924

Benson, R.B.J., 2008, A redescription of 'Megalosaurus' hesperis (Dinosauria, Theropoda) from the Inferior Oolite (Bajocian, Middle Jurassic) of Dorset, United Kingdom: Zootaxa, v. 1931, p. 57-67.

Benson, R.B.J., 2010, A description of Megalosaurus bucklandii (Dinosauria: Theropoda) from the Bathonian of the UK and the relationships of Middle Jurassic theropods: Zoological Journal of the Linnean Society, v. 158, p. $882-935$.

Benson, R.B.J., Carrano, M.T., and. Brusatte, S.L., 2010, A new clade of archaic large-bodied predatory dinosaurs (Theropoda: Allosauroidea) that survived to the latest Mesozoic: Naturwissenschaften, v. 97, p. 71-78.

Benson, R.B.J., Rich, T.H., Vickers-Rich, P., and Hall, M., 2012, Theropod fauna from southern Australia indicates high polar diversity and climatedriven dinosaur provinciality: PLoS ONE, v. 7, doi:10.1371/journal. pone. 0037122
Brochu, C.A., 2003, Osteology of Tyrannosaurus rex: insights from a nearly complete skeleton and high-resolution computed tomographic analysis of the skull: Memoir of the Society of Vertebrate Paleontology, v. 7, p. 1-138.

Brusatte, S.L., Benson, R.B.J., and Hutt, S., 2008, The osteology of Neovenator salerri (Dinosauria: Theropoda) from the Wealden Group (Barremian) of the Isle of Wight: Monograph of the Palaeontographical Society, v. 162, p. 1-166.

Buffetaut, E., Suteethorn, V., and Tong, H., 1996, The earliest known tyrannosaur from the Lower Cretaceous of Thailand: Nature, v. 381, p. 689-691.

Carrano, M.T., and Sampson, S.D., 2008, The phylogeny of Ceratosauria (Dinosauria: Theropoda): Journal of Systematic Palaeontology, v. 6, p. 183-236.

Carrano, M.T., Benson, R.B.J., and Sampson, S.D., 2012, The phylogeny of Tetanurae (Dinosauria: Theropoda): Journal of Systematic Palaeontology, v. 10 , p. $211-300$.

Chure, D.J., 2000, A new species of Allosaurus from the Morrison Formation of Dinosaur National Monument (UT-CO) and a revision of the theropod family Allosauridae [Ph.D. dissertation]: New York, Columbia University, $1021 \mathrm{p}$.

Coria, R.A., and Currie, P.J., 2006, A new carcharodontosaurid (Dinosauria, Theropoda) from the Upper Cretaceous of Argentina: Geodiversitas, v. 28, p. $71-118$.

Coria, R.A., Currie, P., Ortega, F., and Baiano, M., 2017, A possible carcharodontosaurid theropod record from the Valanginian (Early Cretaceous) of Patagonia, Argentina: 77th Annual Meeting of the Society of Vertebrate Paleontology, Calgary, Canada, August 2017, Abstracts book, p. 100.

Cuesta, E., Díaz-Martínez, I., Ortega, F., and Sanz, J.L., 2015, Did all theropods have chicken-like feet? First evidence of a non-avian dinosaur podotheca: Cretaceous Research, v. 56, p. 53-59.

Currie, P.J., 2000, Theropods from the Cretaceous of Mongolia, in Benton, M.J., Shishkin, M.A., Unwin, D.M., and Kurochkin, E.N., eds., The Age of Dinosaurs in Russia and Mongolia, Cambridge, Cambridge University Press, p. 434-455.

Currie, P.J., and Carpenter, K., 2000, A new specimen of Acrocanthosaurus atokensis (Theropoda, Dinosauria) from the Lower Cretaceous Antlers Formation (Lower Cretaceous, Aptian) of Oklahoma, USA: Geodiversitas, v. 22, p. 207-246.

Currie, P.J., and Zhao, X.J., 1993, A new carnosaur (Dinosauria, Theropoda) from the Jurassic of Xinjiang, People's Republic of China: Canadian Journal of Earth Sciences, v. 30, p. 2037-2081.

D’Emic, M.D., Melstrom, K.M., and Eddy, D.R., 2012, Paleobiology and geographic range of the large-bodied Cretaceous theropod dinosaur Acrocanthosaurus atokensis: Palaeogeography, Palaeoclimatology, Palaeoecology, v. 333-334, p. 13-23.

Fowler, D.W., Freedman, E.A., Scannella, J.B., and Kambic, R.E., 2011, The predatory ecology of Deinonychus and the origin of flapping in birds: PLoS ONE, v. 6, doi:10.1371/journal.pone.0028964

Galton, P.M., Carpenter, K., and Dalman, S.G., 2015, The holotype pes of the Morrison dinosaur Camptonotus amplus Marsh, 1879 (Upper Jurassic, western USA) - is it Camptosaurus, Sauropoda or Allosaurus?: Neues Jahrbuch für Geologie und Paläontologie Abhandlungen, v. 275, p. 317-335.

Gauthier, J., 1986, Saurischian monophyly and the origin of birds. in Padian, K., ed., The Origin of Birds and the Evolution of Flight: San Francisco, California Academy of Science, p. 1-55.

Gerke, O., and Wings, O., 2016, Multivariate and cladistic analyses of isolated teeth reveal sympatry of theropod dinosaurs in the Late Jurassic of Northern Germany: PLoS ONE, v. 11, doi:10.1371/journal.pone.0158334

Gilmore, C.W., 1920, Osteology of the carnivorous Dinosauria in the United States National Museum, with special reference to the genera Antrodemus (Allosaurus) and Ceratosaurus: Bulletin of the United States National Museum, v. 110, p. 1-159.

Han, F., Clark, J.M., Xu, X., Sullivan, C., Choiniere, J., and Hone, D.W.E., 2011, Theropod teeth from the Middle-Upper Jurassic Shishugou Formation of northwest Xinjiang, China: Journal of Vertebrate Paleontology, v. 31, p. 111-126.

Hanson, M., and Makovicky, P.J., 2013, A new specimen of Torvosaurus tanneri originally collected by Elmer Riggs: Historical Biology, v. 26, p. 775-784.

Hendrickx, C., and Mateus, O., 2014a, Abelisauridae (Dinosauria: Theropoda) from the Late Jurassic of Portugal and dentition-based phylogeny as a contribution for the identification of isolated theropod teeth: Zootaxa, v. 3759, p. $1-74$.

Hendrickx, C., and Mateus, O., 2014b, Torvosaurus gurneyi n. sp., the largest terrestrial predator from Europe, and a proposed terminology of the maxilla anatomy in nonavian theropods: PLoS ONE, v. 9, doi:10.1371/journal. pone. 0088905

Hill, G., 1988, The sedimentology and lithostratigraphy of the Upper Jurassic Lourinhã Formation, Lusitanian Basin Portugal. [Ph.D. dissertation]: Milton Keynes, UK, The Open University, 292 p. 
Hocknull, S.A., White, M.A., Tischler, T.R., Cook, A.G., Calleja, N.D., Sloan, T., Elliott, D.A., 2009, New mid-Cretaceous (Latest Albian) dinosaurs from Winton, Queensland, Australia: PLoS ONE, v. 4, doi:10.1371/journal. pone. 0006190

Hutt, S., Martill, D.M., and Barker, M.J., 1996, The first European allosauroid dinosaur (Lower Cretaceous, Wealden Group, England): Neues Jahrbuch für Geologie und Paläontologie Monatshefte, v. 1996, p. 635-644.

Kullberg, J.C., Rocha, R.B., Soares, A.F., Rey, J., Terrinha, P., and Callapez, P., 2006, A Bacia Lusitaniana: estratigrafia, paleogeografia e tectónica, in Dias, R., Araújo, A., Terrinha, P., and Kullberg, J.C., eds., Geologia de Portugal no Contexto da Ibéria: Évora, Portugal, Universidade de Évora, p. 317-368

Lapparent, A.F., and Zbyszewski, G., 1957, Les dinosauriens du Portugal: Memórias dos Serviços Geológicos de Portugal, v. 2, p. 1-63.

Leinfelder, R.R., 1993, A sequence stratigraphic approach to the Upper Jurassic mixed carbonate-siliciclastic succession of the central Lusitanian Basin, Portugal: Profil, v. 5, p. 119-140.

Lennier, G., 1870, Études Géologiques et Paléontologiques sur l'Embouchure de la Seine et les Falaises de la Haute-Normandi: Havre, Imprimerie Eugéne Costey, 245 p.

Madsen, J.H. Jr., 1976, Allosaurus fragilis: a revised osteology: Utah Geological and Mineralogical Survey, v. 109, p. 1-163.

Malafaia, E., Ortega, F., Escaso, F., Silva, B., Ramalheiro, G., Dantas, P., Moniz, C., and Barriga, F., 2007, A preliminary account of a new Allosaurus individual from the Lourinhã Group (Upper Jurassic of Torres Vedras, Portugal): IV International Symposium about Dinosaurs Palaeontology and their Environment, Salas de los Infantes, Spain 2007, Abstracts book, p. 243-251.

Malafaia, E., Ortega, F., Escaso, F., Dantas, P., Pimentel, N., Gasulla, J.M., Ribeiro, B., Barriga, F., and Sanz, J.L., 2010, Vertebrate fauna at the Allosaurus fossil-site of Andrés (Upper Jurassic), Pombal, Portugal: Journal of Iberian Geology, v. 36, p. 193-204.

Malafaia, E., Ortega, F., and Escaso, F., 2014, New post-cranial elements assigned to coelurosaurian theropods from the Late Jurassic of Lusitanian Basin, Portugal: Fundamental, v. 24, p. 123-126.

Malafaia, E., Ortega, F., Escaso, F., and Silva, B., 2015, New evidence of Ceratosaurus (Dinosauria: Theropoda) from the Late Jurassic of the Lusitanian Basin, Portugal: Historical Biology, v. 27, p. 938-946.

Malafaia, E., Mocho, P., Escaso, F., and Ortega, F., 2017, A juvenile allosauroid theropod (Dinosauria, Saurischia) from the Upper Jurassic of Portugal: Historical Biology, v. 29, p. 654-676.

Manuppella, G., Antunes, M.T., Pais, J., Ramalho, M.M., and Rey, J., 1999, Notícia explicativa da Folha 30-A, Lourinhã: Departamento de Geologia do Instituto Geológico e Mineiro, Lisboa, unpg.

Marsh, O.C., 1878, Notice of new dinosaurian reptiles: American Journal of Science and Arts, series 5, v. 15, p. 241-244.

Marsh, O.C., 1881, Principal characters of American Jurassic dinosaurs: American Journal of Science, series 5, v. 21, p. 417-423.

Mateus, O., 1998, Lourinhanosaurus antunesi, a new upper Jurassic allosauroid (Dinosauria: Theropoda) from Lourinhã, Portugal: Memórias da Academia de Ciências de Lisboa, v. 37, p. 111-124.

Mateus, O., 2005, Dinossauros do Jurássico Superior de Portugal com destaque para os saurísquios [Ph.D. dissertation]: Lisbon, Universidade Nova de Lisboa, $375 \mathrm{p}$.

Mateus, O., and Antunes, M.T., 2000a, Ceratosaurus sp. (Dinosauria: Theropoda) in the Late Jurassic of Portugal: 31st International Geological Congress, Rio de Janeiro, Brazil, 2000, Abstract Volume, p. 1

Mateus, O., and Antunes, M.T., 2000b, Torvosaurus sp. (Dinosauria: Theropoda) in the Late Jurassic of Portugal: I Congresso Ibérico de Paleontología/XVI Jornadas de la Sociedad Española de Paleontología, Évora Portugal, 2000, Abstracts Book, p. 115-117.

Mateus, O., Walen, A., and Antunes, M.T., 2006, The large theropod fauna of the Lourinhã Formation (Portugal) and its similarity to the Morrison Formation, with a description of a new species of Allosaurus, in Foster, J.R. and Lucas, S.G. eds., Paleontology and Geology of the Upper Jurassic Morrison Formation: New Mexico Museum of Natural History and Science Bulletin, 36, p. 123-129.

Matos, R., 1954, Carta Geológica de Portugal, Serviços Geológicos de Portugal, Folha 30-C, Torres Vedras, scale 1:50 000

Mocho, P., Royo-Torres, R., Malafaia, E., Escaso, F., and Ortega, F., 2016, Systematic review of Late Jurassic sauropods from the Museu Geológico collections (Lisboa, Portugal): Journal of Iberian Geology, v. 42, p. 227-250.

Moniz, C., Carvalho, C., Dantas, P., Ortega, F., Malafaia, E., Ramalheiro, G., Escaso, F., Silva, B., and Barriga, F., 2007, Aspectos tafonómicos de un terópodo del yacimiento de Cambelas (Jurásico Superior, Torres Vedras, Portugal): IV Jornadas Internacionales sobre Paleontología de Dinosaurios y su Entorno, Salas de los Infantes, Spain, 2007, Abstracts Book, p. 81-83.
Oliveira, J.T., Pereira, H., Ramalho, M., and Antunes, M.T., 1992, Carta Geológica de Portugal, Serviços Geológicos de Portugal, scale 1:500 0000.

Ortega, F., Escaso, F., Gasulla, J.M., Dantas, P., and Sanz, J.L., 2006, Dinosaurios de la Península Ibérica: Estudios Geológicos, v. 62, p. 219-240.

Ortega, F., Escaso, F., and Sanz, J.L., 2010, A bizarre, humped Carcharodontosauria (Theropoda) from the Lower Cretaceous of Spain: Nature, v. 467 , p. 203-206.

Owen, R., 1842, Report on British fossil reptiles, part II: Report of the British Association for the Advancement of Science, v. 11, p. 60-204.

Paul, G.S., 1988, Predatory Dinosaurs of the World: A Complete Illustrated Guide: New York, Simon and Schuster, $464 \mathrm{p}$.

Pérez-Moreno, B.P., Sanz, J.L., Sudre, J., and Sigé, B., 1993, A theropod dinosaur from the Lower Cretaceous of southern France: Revue de Paléobiologie, v. 7, p. 173-188.

Pérez-Moreno, B.P., Chure, D.J, Pires, C., Silva, C.M., Santos, V., Dantas, P. Póvoas, L., Cachão, M., Sanz, J.L., and Galopim de Carvalho, A.M., 1999, On the presence of Allosaurus fragilis (Theropoda: Carnosauria) in the Upper Jurassic of Portugal: first evidence of an intercontinental dinosaur species: Journal of the Geological Society, v. 156, p. 449-452.

Persons, S.W., and Currie, P.J., 2011, Dinosaur speed demon: the caudal musculature of Carnotaurus sastrei and implications for the evolution of South American abelisaurids: PLoS ONE, v. 6, doi:10.1371/journal. pone. 0025763

Rauhut, O.W.M., 2003a, A tyrannosauroid dinosaur from the Upper Jurassic of Portugal: Palaeontology, v. 46, p. 903-910.

Rauhut, O.W.M., 2003b, The interrelationships and evolution of basal theropod dinosaurs: Special Papers in Palaeontology, v. 69, p. 1-213.

Rauhut, O.W.M., 2011, Theropod dinosaurs from the Late Jurassic of Tendaguru (Tanzania): Special Papers in Palaeontology, v. 86, p. 195-239.

Rauhut, O.W.M., and Carrano, M.T., 2016, The theropod dinosaur Elaphrosaurus bambergi Janensch, 1920, from the Late Jurassic of Tendaguru, Tanzania: Zoological Journal of the Linnean Society, doi:10.1111/ zoj. 12425

Rauhut, O.W.M., and Fechner, R., 2005, Early development of the facial region in a non-avian theropod dinosaur: Proceedings of the Royal Society B: Biological Sciences, v. 272, p. 1179-1183.

Rauhut, O.W.M., Hübner, T.R., and Lansen, K.-P., 2016, A new megalosauri theropod dinosaur from the late Middle Jurassic (Callovian) of northwestern Germany: implications for theropod evolution and faunal turnover in the Jurassic: Palaeontologia Electronica 19.2.26A, p. 1-65, palaeoelectronica.org/content/2016/1536

Rey, J., 1993, Les unités lithostratigraphiques du Grupe de Torres Vedras (Estremadura, Portugal): Comunicações do Instituto Geológico e Mineiro, v. 79 , p. $75-85$

Rusell, D., 1972, Ostrich dinosaurs from the Late Cretaceous of western Canada: Canadian Journal of Earth Sciences, v. 9, p. 376-402.

Sauvage, H.E., 1897-1898, Vértébrés fossiles du Portugal. Contribution à l'étude des poissons et des reptiles du Jurassique et du Crétacique: Memoires Direction des Travaux Géologiques du Portugal, p. 1-48.

Schneider, S., Fürsich, F.T., and Werner, W., 2009, Sr-isotope stratigraphy of the Upper Jurassic of central Portugal (Lusitanian Basin) based on oyster shells: International Journal of Earth Sciences, v. 98, p. 1949-1970.

Sereno, P.C., Wilson, J.A., Larsson, H.C.E., Dutheil, D.B., and Sues, H.-D., 1994, Early Cretaceous dinosaurs from the Sahara: Science, v. 266, p. $267-$ 270.

Taylor, A.M., Gowland, S., Leary, S., Keogh, K.J., and Martinius, A.W., 2014, Stratigraphical correlation of the Lourinhã Formation in the Consolação Sub-basin (Lusitanian Basin), Portugal: Geological Journal, v. 49, p. $143-162$.

Wilson, J.A., 1999, A nomenclature for vertebral laminae in sauropods and other saurischian dinosaurs: Journal of Vertebrate Paleontology, v. 19, p. 639653.

Wilson, J.A., D'Emic, M.D., Ikejiri, T., Moacdieh, E.M., and Whitlock, J.A., 2011, A nomenclature for vertebral fossae in sauropods and other saurischian dinosaurs: PloS ONE, v. 6, doi:10.1371/journal.pone.0017114

Zbyszewski, G., Moitinho de Almeida, F., and Torres de Assunção, C., 1955, Carta geológica de Portugal e notícia explicativa: Serviços Geológicos de Portugal, Lisboa, Folha 30-C, Torres Vedras: rochas eruptivas, scale 1:50 000

Zinke, J., 1998, Small theropod teeth from the Upper Jurassic coal mine of Guimarota (Portugal): Paläontologische Zeitschrift, v. 72, p. 179-189. 